\title{
əEvaluating Model Simulations of Twentieth-Century Sea-Level Rise. Part II: Regional Sea-Level Changes ${ }^{\mathscr{a}}$
}

\author{
B. Meyssignac, ${ }^{\text {a }}$ A. B. A Slangen, ${ }^{\text {b }}$ A. Melet,${ }^{\mathrm{c}}$ J. A. Church,${ }^{\mathrm{d}}$ X. Fettweis, ${ }^{\mathrm{e}}$

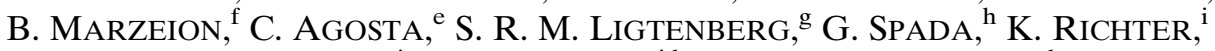 \\ M. D. PAlmer, ${ }^{\mathrm{j}}$ C. D. Roberts,${ }^{\mathrm{j}, \mathrm{k}}$ AND N. ChAMPOLLION ${ }^{1}$ \\ ${ }^{a}$ LEGOS, Université de Toulouse, CNES, CNRS, IRD, UPS, Toulouse, France \\ ${ }^{\mathrm{b}}$ Department of Estuarine and Delta Systems, Royal Netherlands Institute for Sea Research, Yerseke, Netherlands \\ ${ }^{\mathrm{c}}$ Mercator Ocean, Ramonville, France \\ ${ }^{\mathrm{d}}$ Climate Change Research Centre, University of New South Wales, Sydney, New South Wales, Australia \\ ${ }^{\mathrm{e}}$ University of Liège, Liege, Belgium \\ ${ }^{\mathrm{f}}$ Institute of Geography, University of Bremen, Bremen, Germany \\ ${ }^{\mathrm{g}}$ Institute for Marine and Atmospheric research Utrecht, Utrecht University, Utrecht, Netherlands \\ ${ }^{\mathrm{h}}$ University of Urbino, Urbino, Italy \\ ${ }^{\mathrm{i}}$ University of Innsbruck, Innsbruck, Austria \\ ${ }^{\mathrm{j}}$ Met Office Hadley Centre, Exeter, United Kingdom \\ ${ }^{\mathrm{k}}$ European Centre for Medium-Range Weather Forecasts, Shinfield, United Kingdom \\ ${ }^{1}$ International Space Science Institute, Bern, Switzerland
}

(Manuscript received 22 February 2017, in final form 6 July 2017)

\begin{abstract}
Twentieth-century regional sea level changes are estimated from 12 climate models from phase 5 of the Climate Model Intercomparison Project (CMIP5). The output of the CMIP5 climate model simulations was used to calculate the global and regional sea level changes associated with dynamic sea level, atmospheric loading, glacier mass changes, and ice sheet surface mass balance contributions. The contribution from groundwater depletion, reservoir storage, and dynamic ice sheet mass changes are estimated from observations as they are not simulated by climate models. All contributions are summed, including the glacial isostatic adjustment (GIA) contribution, and compared to observational estimates from 27 tide gauge records over the twentieth century (1900-2015). A general agreement is found between the simulated sea level and tide gauge records in terms of interannual to multidecadal variability over 1900-2015. But climate models tend to systematically underestimate the observed sea level trends, particularly in the first half of the twentieth century. The corrections based on attributable biases between observations and models that have been identified in Part I of this two-part paper result in an improved explanation of the spatial variability in observed sea level trends by climate models. Climate models show that the spatial variability in sea level trends observed by tide gauge records is dominated by the GIA contribution and the steric contribution over 1900-2015. Climate models also show that it is important to include all contributions to sea level changes as they cause significant local deviations; note, for example, the groundwater depletion around India, which is responsible for the low twentieth-century sea level rise in the region.
\end{abstract}

Denotes content that is immediately available upon publication as open access.

Supplemental information related to this paper is available at the Journals Online website: https://dx.doi.org/10.1175/JCLID-17-0112.s1.

Corresponding author: Benoit Meyssignac, benoit.meyssignac@ legos.obs-mip.fr

\section{Introduction}

Tide gauge records and satellite observations show that sea level has risen during the twentieth century and that this rise has not been spatially uniform (Church and White 2011; Meyssignac and Cazenave 2012; Wöppelmann et al. 2009; Slangen et al. 2014b). Processbased projections indicate that global mean sea level will almost certainly accelerate through the twenty-first century in response to greenhouse gas (GHG) emissions 
and associated global warming (Church et al. 2013b). However, the magnitude of this rise and its spatial variations remain uncertain because of uncertainties in GHG emissions and in model representation of climate change and because of inherent uncertainty associated with the chaotic nature of the climate variability. This is an important issue, as coastal communities need reliable projections to prepare adaptation plans for future sea level rise.

The Fifth Assessment Report (AR5) of the Intergovernmental Panel on Climate Change (IPCC) projected that global sea level will rise by $40 \pm 14 \mathrm{~cm}$ [ $66 \%$ confidence level (CL)] and $63 \pm 19 \mathrm{~cm}(66 \% \mathrm{CL})$ under low- and high-end GHG emission scenarios, respectively, by 2081-2100 (with respect to 1986-2005). Irrespective of the GHG emission scenario, this global rise will be accompanied by regional variations of mostly up to $\pm 30 \%$ of the global rise (Church et al. 2013b; Slangen et al. 2014a). These projections are based on simulations of the twenty-first century climate from CMIP5 (Taylor et al. 2012), and their reliability and uncertainty depends on the quality of the climate models used. In this work, we evaluate the ability of CMIP5 climate models to reproduce observed sea level rise over the twentieth century. The objectives are 1) to evaluate climate models' ability to simulate regional sea level changes and to identify and understand potential limitations of these models and 2) to determine the causes of the temporal and regional variations in the twentieth-century sea level rise.

In Part I of this two-part paper (Slangen et al. 2017, hereafter Part I), we have evaluated global mean sea level (GMSL) change estimated from CMIP5 climate models by comparison with observation-based reconstructions of GMSL using tide gauge estimates [from Hay et al. (2015), Jevrejeva et al. (2014), Church et al. (2011), and Ray and Douglas (2011)] and satellite altimetry for the periods 1900-2015 and 1993-2015, respectively. We found that CMIP5 models generally underestimate the global sea level change over the twentieth century but that they compare more favorably for the more recent period of 1970-2015, when observations from tide gauge records are more reliable and the anthropogenic forcing is dominant (Slangen et al. 2016). The model-simulated contributions [thermal expansion, glacier mass loss, ice sheet mass balance, and glacial isostatic adjustment (GIA)] allowed us to explain $50 \% \pm 30 \%(1.65 \sigma)$ of the mean observed change for 1901-20 versus 1988-2007 (see Part I). Based on biases between observations and models (see Part I for more details), we added bias corrections for Greenland surface mass balance (SMB), glaciers, and the deep ocean/ long term ice sheet, which resulted in an improved explanation of $75 \% \pm 38 \%$ of the observed change. These small (mostly early twentieth century) corrections are likely related to longer-term variability or change rather than anthropogenic forcing. For the more recent satellite period (from 1993 onward), the explained percentage increased to $102 \% \pm 33 \%(105 \% \pm 35 \%$ when corrections were included). In this later period, the uncertainties in the observations are smaller as the data resolution is better, both spatially and temporally. In this paper, we focus on the regional variations of twentieth-century relative sea level change (i.e., relative to "solid" Earth) and assess to what extent climate models can reproduce the observed regional departures from GMSL.

Regional sea level reconstructions based on tide gauge records (e.g., Ray and Douglas 2011; Church and White 2011; Meyssignac et al. 2012; Wenzel and Schröter 2010) and ocean general circulation models (e.g., Lombard et al. 2009; Balmaseda et al. 2013; Köhl 2015; Chepurin et al. 2014) indicate that sea level changes have substantial regional departures from GMSL at decadal to multidecadal time scales. There are three main underlying processes responsible for these deviations: 1 ) the dynamical response of the ocean to the atmospheric forcing (e.g., Gregory et al. 2001; Stammer et al. 2013; Forget and Ponte 2015), 2) changes in the atmospheric pressure loading induced by changes in the atmospheric circulation and moisture content (Wunsch and Stammer 1997; Stammer and Hüttemann 2008), and 3) the solid Earth deformation and effects on Earth's geoid (arising from both gravitational and rotational effects) associated with glacier and ice sheet mass change (Gomez et al. 2010; Milne et al. 2009; Mitrovica et al. 2001), reservoir storage changes, groundwater depletion (Wada et al. 2012), and glacial isostatic adjustment (Argus et al. 2014; Peltier et al. 2015; A et al. 2013).

Here we estimate the regional sea level changes between 1900 and 2015, primarily using the output of the CMIP5 climate model simulations. We build upon recent progress in projecting the contributions to sea level at regional scale from climate models (Carson et al. 2016; Bilbao et al. 2015; Slangen et al. 2014a,b; Kopp et al. 2014; Spada et al. 2013; Perrette et al. 2013, Church et al. 2011) but focus on the historical changes. We use CMIP5 climate models to estimate the global and regional sea level changes associated with ocean density and circulation changes ("dynamic sea level" hereafter; Lowe and Gregory 2006; Griffies et al. 2014) and the contribution from changes in atmospheric loading ("inverse barometer effect" hereafter; Wunsch and Stammer 1997) (see section 2). Glacier mass changes and ice sheet SMB are also estimated from CMIP5 outputs using offline models. The contribution from 
TABLE 1. Ensemble of 12 CMIP5 climate models used to estimate the twentieth-century sea level rise.

\begin{tabular}{|c|c|c|c|c|}
\hline Model ID & Institute, country & $\begin{array}{l}\text { Atmosphere grid } \\
\text { resolution (horizontal } \\
\text { grid; No. of } \\
\text { vertical levels) }\end{array}$ & $\begin{array}{l}\text { Ocean grid resolution } \\
\text { (horizontal grid; } \\
\text { No. of vertical levels) }\end{array}$ & Main reference \\
\hline CanESM2 & $\begin{array}{l}\text { Canadian Centre for Climate } \\
\text { Modeling and Analysis, Canada }\end{array}$ & Spectral T63; 35 & $1.41^{\circ} \times 0.94^{\circ} ; 40$ & $\begin{array}{l}\text { Arora et al. (2011) } \\
\text { von Salzen et al. (2013) }\end{array}$ \\
\hline CCSM4 & $\begin{array}{l}\text { National Center for Atmospheric } \\
\text { Research, United States }\end{array}$ & $0.9^{\circ} \times 1.25^{\circ} ; 27$ & $\begin{array}{l}1^{\circ} \text { on average } \\
\quad\left(\text { lon: } 1.125^{\circ}\right. \\
\left.\text { lat: } 0.27^{\circ}-0.64^{\circ}\right) ; 60\end{array}$ & Gent et al. (2011) \\
\hline CNRM-CM5 & $\begin{array}{l}\text { Météo-France/Centre National de } \\
\text { Recherches Météorologiques, } \\
\text { France }\end{array}$ & TL $127 ; 31$ & $0.7^{\circ}$ on average; 42 & Voldoire et al. (2013) \\
\hline GFDL-CM3 & $\begin{array}{l}\text { National Oceanic and Atmospheric } \\
\text { Administration, Geophysical Fluid } \\
\text { Dynamics Laboratory, United States }\end{array}$ & ２00 km C48L48; 48 & $\begin{array}{l}1^{\circ} \text { tripolar } 360 \times \\
\text { 200L50; } 50\end{array}$ & $\begin{array}{l}\text { Delworth et al. (2006) } \\
\text { Donner et al. (2011) }\end{array}$ \\
\hline GISS-E2-R & $\begin{array}{l}\text { National Aeronautics and Space } \\
\text { Administration, Goddard Institute } \\
\text { for Space Studies, United States }\end{array}$ & $2^{\circ} \times 2.5^{\circ} ; 40$ & $1^{\circ} \times 1.25^{\circ} ; 32$ & Schmidt et al. (2006) \\
\hline HadGEM2-ES & $\begin{array}{l}\text { Hadley Center for Climate } \\
\text { Prediction and Research/Met } \\
\text { Office, United Kingdom }\end{array}$ & $1.25^{\circ} \times 1.875^{\circ} ; 38$ & $1^{\circ}-0.3^{\circ} \times 1^{\circ} ; 40$ & Collins et al. (2011) \\
\hline IPSL-CM5A-LR & Institut Pierre Simon Laplace, France & $1.9^{\circ} \times 3.75^{\circ} ; 39$ & $2^{\circ}-0.5^{\circ} \times 2^{\circ} ; 31$ & Dufresne et al. (2012) \\
\hline MIROC5 & The University of Tokyo, Japan & $1.4^{\circ} \times 1.4^{\circ} \mathrm{T} 85 ; 40$ & $1.4^{\circ}-0.5^{\circ} \times 1.4^{\circ} ; 50$ & Watanabe et al. (2010) \\
\hline MIROC-ESM & & $2.8^{\circ} \times 2.8^{\circ} \mathrm{T} 42 ; 80$ & $1.4^{\circ}-0.5^{\circ} \times 1.4^{\circ} ; 44$ & Watanabe et al. (2011) \\
\hline MPI-ESM-LR & $\begin{array}{l}\text { Max Planck Institute for Meteorology, } \\
\text { Germany }\end{array}$ & $\sim 1.8^{\circ} \mathrm{T} 63 ; 95$ & $\sim 1.5^{\circ} \mathrm{GR} 15 ; 40$ & $\begin{array}{l}\text { Stevens et al. (2013), } \\
\quad \text { Jungclaus et al. (2013) }\end{array}$ \\
\hline MRI-CGCM3 & $\begin{array}{l}\text { Meteorological Research Institute, } \\
\text { Japan }\end{array}$ & $320 \times 160$ TL159; 48 & $0.5^{\circ} \times 1^{\circ} ; 50$ & Yukimoto et al. (2012) \\
\hline NorESM1-M & Norwegian Climate Center, Norway & $1.9^{\circ} \times 2.5^{\circ} ; 26$ & $1.125^{\circ} ; 53$ & Tjiputra et al. (2013) \\
\hline
\end{tabular}

groundwater depletion, reservoir storage, and dynamic ice sheet mass changes are estimated from observations (Döll et al. 2014; Wada et al. 2016; Shepherd et al. 2012; see section 3 ). The sea level change patterns associated with land-based ice and water mass changes are computed with a sea level equation solver (section 3). All contributions are then summed to provide the first twentieth-century estimate of the regional sea level changes from climate models (section 4). Finally, we discuss the relative importance of each contribution to the local sea level rise, compare the total sea level estimate with tide gauge records (section 4), and analyze the differences between observed and simulated sea level change. In the last section we also discuss potential contributions that we have identified in the companion paper (Part I) and that we think should be included in the comparison between model-based estimates and observations. These contributions are all based on observational evidence but are currently absent or poorly represented in climate models. The primary goal of this paper is to assess the forced signal in sea level that is present in climate models (through trend analysis) while the secondary objective is to assess the regional sea level variability at interannual and decadal time scales.

\section{Contributions to the twentieth-century sea level changes from dynamic sea level and atmospheric pressure loading}

The analysis here is based on the same ensemble of climate models as that used in the global mean sea level companion paper (Part I). It is an ensemble of 12 CMIP5 climate models, which provide the required variables for this study (see Table 1). We used the outputs of the historical simulations from 1900 to 2005 extended until 2015 with the outputs of the high-end GHG emission scenario for the twenty-first century [scenario RCP8.5; see van Vuuren et al. (2011) for an overview of the different representative concentration pathways (RCPs)]. All data have been computed on the native grid of each climate model but they are shown on a common $1^{\circ} \times 1^{\circ}$ grid.

\section{a. Contribution from dynamic sea level}

The dynamic sea level (DSL) is the sea surface height with respect to the geoid that is determined by the dynamical balance associated with ocean density and circulation. DSL variations are related to changes in density of the water columns and changes in the ocean bottom pressure (Gill and Niller 1973). The changes in ocean bottom pressure represent the redistribution of 
mass by the ocean circulation in response to the atmospheric forcing. This does not include here the changes in the mass of the ocean associated with glacier and ice sheet mass loss or land water storage changes. The density term (steric sea level) is associated with changes in the temperature (thermosteric sea level) and salinity (halosteric sea level) of the water columns. At global scale, the mass redistribution component averages out and salinity changes have a negligible effect on global mean sea level, such that changes in global mean sea level can be estimated accurately by the global mean thermosteric sea level (Lowe and Gregory 2006). At regional scale, DSL variations are dominated by the steric component with a small but sizeable contribution in the middle and high latitudes from the mass redistribution component (Forget and Ponte 2015; Meyssignac et al. 2017b).

To estimate the DSL changes from CMIP5 models, we use the sea level field named "zos," which includes both the mass redistribution and steric components of sea level. In most CMIP5 models, the ocean module is based on the Boussinesq approximation and conserves volume rather than mass (Griffies and Greatbatch 2012). As a consequence, the zos output of CMIP5 models is computed from the ocean volume conservation equation rather than the mass conservation equation and does not include the effect of the global mean thermal expansion (Greatbatch 1994; Griffies and Greatbatch 2012). To correct for this, we estimate the global averaged thermosteric sea level from the monthly 3D temperature fields ("thetao" output) of the CMIP5 models (we do not use the "zostoga" field, which is inconsistent between models in particular because of the use of different global masks in different climate model simulations; see Part I) and we add it to the zos fields. The monthly $3 \mathrm{D}$ potential temperature fields of the CMIP5 models were first converted into in situ temperature fields [using the methodology of Bryden (1973)]. From the 3D in situ temperature fields, we computed the thermosteric sea level using the United Nations Educational, Scientific and Cultural Organization (UNESCO) 1980 international equation of state (IES80). A global average over the ocean was computed for each model on its own grid, excluding the marginal seas and lakes (the Mediterranean Sea, Red Sea, Black Sea, Caspian Sea, Baltic Sea, Sea of Japan, Persian Gulf, Hudson Bay, and Great Lakes) where the simulated temperature fields are not reliable [see, e.g., Adloff et al. (2017) for the case of the Mediterranean]. We also estimate steric sea level changes from the 3D in situ temperature and salinity fields ("so" output) following the same method as for thermosteric sea level.
Ocean variables in climate model simulations are subject to "drift"- that is, spurious trends in state variables that occur due to insufficient spinup time for the ocean to reach quasi-equilibrium and/or imperfect representation of the Earth system energy budget (e.g., Sen Gupta et al. 2013; Hobbs et al. 2016). DSL and steric sea level are depth-integrated quantities and therefore our historical simulations must be drift corrected so that the climate change signals are not obscured. To avoid removing physical trends in the historical simulations associated with the ocean warming response to GHG emissions or with some centennial climate variability, the long-term spurious drift is estimated by a linear fit at each grid point of the multicentennial climate models control runs in which GHG concentrations are held constant at the preindustrial level [as in Bilbao et al. (2015)]. In addition, Hobbs et al. (2016) have shown that a linear drift correction is sufficient to ensure approximate energy budget closure in CMIP5 models. The linear drift correction is applied to climate models at each grid point for the extended historical simulations.

Explosive volcanic eruptions produce aerosols in the stratosphere, which act to cool the Earth system by reducing the net incoming solar radiation. The associated decrease in ocean heat content leads to a corresponding drop in sea level due to thermal contraction. Following a major volcanic eruption the rate of ocean heat uptake and associated sea level rise is enhanced for a few decades (Church et al. 2005) but the net effect of volcanic activity on the climate system is to reduce ocean heat content and therefore sea level. Gregory (2010) and Gregory et al. (2013b) showed that for climate models that omitted the volcanic forcing in their control simulation, the imposition of historical volcanic forcing in the historical simulation represented a time-mean negative forcing in the historical simulation relative to the control simulation and resulted in a small bias in estimates of the twentieth-century global thermal expansion. It is not simple to correct for this bias because the correction is model-dependent as different models show different sensitivities to the volcanic forcing (Gregory et al. 2013b) and part of it may be already compensated for by the tuning of model historical simulations in order to reproduce key climate metrics such as the surface temperature (Melet and Meyssignac 2015). In Part I we estimated the volcanic correction for GMSL by fitting a trend to the global thermosteric sea level from the historical natural-only simulations in which the historical volcanic activity and solar activity are imposed over the twentieth century while the anthropogenic GHG and aerosols concentrations are kept constant at the preindustrial level. This method cannot be used at regional scale to correct the regional DSL because at this scale 


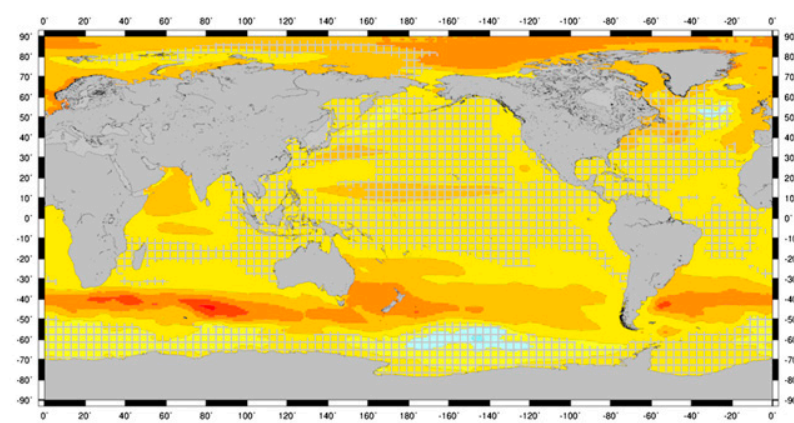

a)
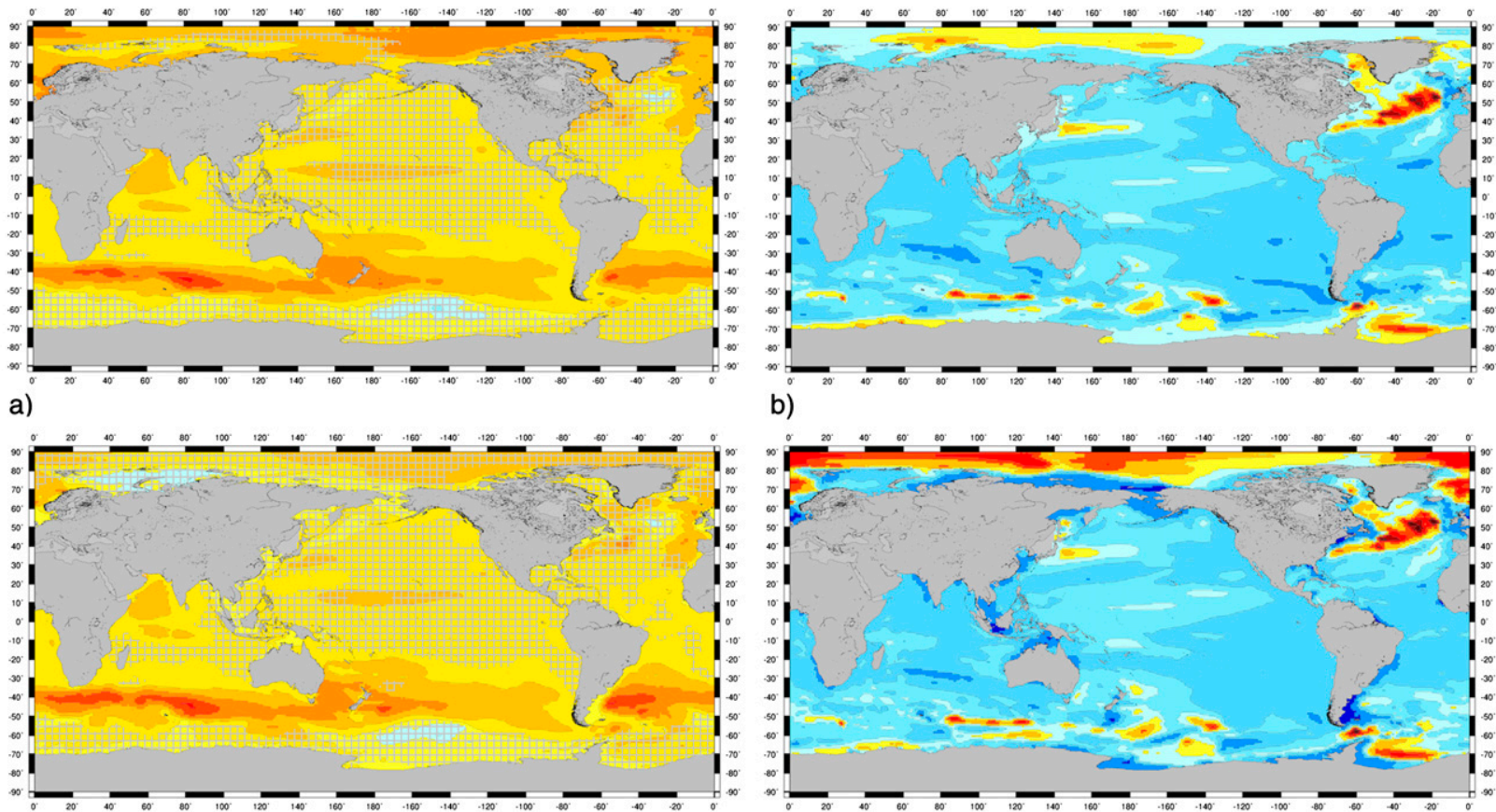

c)

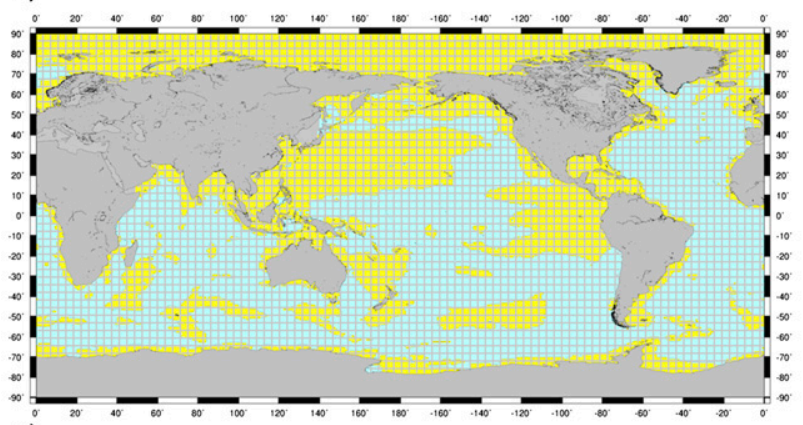

e)

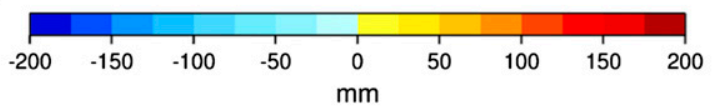

b)

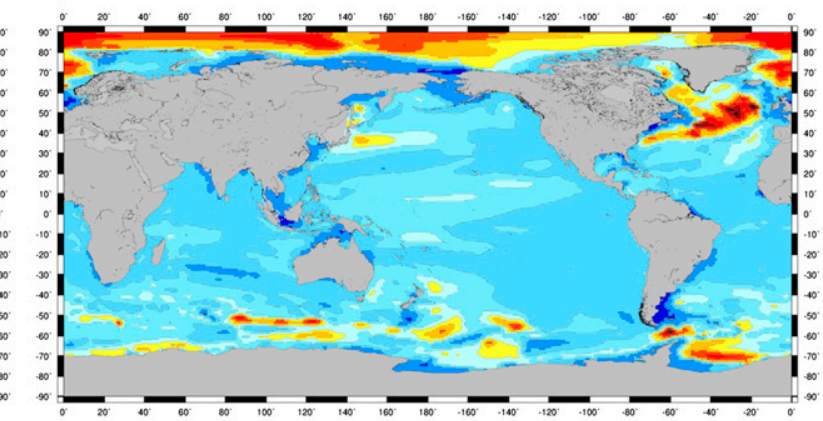

d)

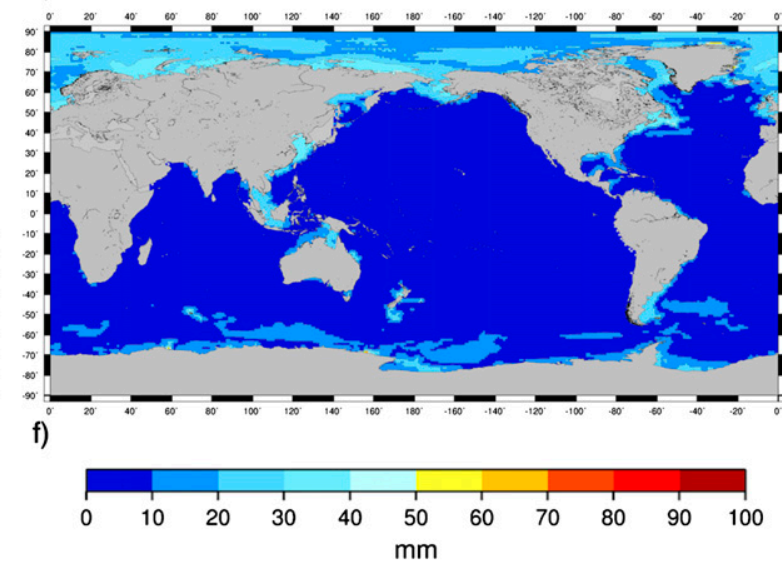

FIG. 1. (left) Ensemble mean of the time-averaged (a) DSL changes (including the global thermal expansion), (c) steric sea level changes, and (e) bottom pressure changes for the period 1996-2015 relative to the reference period 1901-20 (mm) computed from the historical and RCP8.5 simulations; (a) and (c) include the globally averaged thermosteric sea level increase of $0.046 \pm 0.02 \mathrm{~m}$. (right) RMS spread of the individual model result around the ensemble mean for (b) DSL, (d) steric sea level, and (f) bottom pressure (mm). In (a), (c), and (e) red indicates sea level rise and blue indicates sea level fall. The hatched areas indicate regions where the ensemble mean signal is smaller than 1.65 standard deviations of the ensemble spread (i.e., the $90 \% \mathrm{CL}$ ).

the trends in thermosteric sea level from the historical natural simulations are dominated by the internal variability rather than the volcanic forcing effect. To search for the spatial distribution of the volcanic correction is beyond the scope of this study. We choose here to apply only the global volcanic correction (with the same values as in Part I) and to ignore any regional component.

The extended historical runs show a range of spatial patterns in dynamic sea level change between 1901-20 and 1996-2015 (see Fig. S1 in the online supplemental material). The ensemble mean of these patterns (see Fig. 1a) shows typical features of the sea level response to GHG emissions, which can be seen in the model mean of CMIP5 simulations under the idealized $1 \% \mathrm{CO}_{2}$ scenario (Bouttes and Gregory 2014) or in twenty-firstcentury projections of sea level when GHG emissions become the dominant external forcing (Pardaens et al. 2011; Yin 2012; Yin et al. 2010; Bilbao et al. 2015). These features include a global thermal expansion of the ocean in response to the global warming (Slangen et al. 2014a, 
2015) and a meridional dipole in the Southern Ocean (see Fig. 1a), which is associated with changes in westerly winds and heat fluxes in the Southern Ocean and in wind-driven overturning circulation changes (Gregory et al. 2016; Bouttes and Gregory 2014) in response to both GHG emissions and ozone depletion (Cai 2006; Fyfe et al. 2007).

Although the models show some common features, the individual models disagree on the detailed spatial distribution and the magnitude of the regional changes over the twentieth century (in particular at high latitudes; see Figs. 1b and S1). Potential explanations for this disagreement are differences in climate model simulations of the sea level forced response and the sea level unforced internal variability associated with phenomena such as El Niño-Southern Oscillation (ENSO), the interdecadal Pacific oscillation (IPO), or Atlantic multidecadal variability (AMV). The unforced variability is spontaneously generated within the climate system and cannot be expected to be in phase in climate model simulations. It is substantial at interannual to multidecadal time scales (Fig. S4; see also Lyu et al. 2016; Bordbar et al. 2015) and it masks part of the forced signal during the twentieth century (Carson et al. 2015; Richter and Marzeion 2014; Lyu et al. 2014; Jordà 2014). Here the unforced variability explains a significant part of the spread among climate models' twentieth-century dynamic sea level change patterns (cf. Fig. S4 and Fig. 1b), but there are also other potential explanations such as differences among climate models in grid resolution (horizontal and vertical) in the parameterization or in the representation of climate processes (in particular atmospheric, oceanic, and sea ice processes at high latitude).

Most of the dynamical sea level change pattern is explained by the steric sea level changes (see Figs. 1c and S2). The redistribution of mass within the ocean is actually negligible everywhere (see Figs. 1d and S3) except on the shelves. On the shelves, the shallow water columns permit smaller steric expansion compared to that of deep-water columns. It results in a steric sea surface height gradient across shelves along the twentieth century, as the ocean warms. This gradient cannot be balanced by geostrophy; it is actually compensated by a mass redistribution onto the shelves reducing the total gradient in sea level across the shelves (Landerer et al. 2007).

Over the entire ocean the spread among climate models twentieth-century steric sea level change is large ( $\pm 78 \%$ of the ensemble mean signal on average over the ocean; $90 \%$ CL). It is maximum in the Arctic and in the Gulf Stream extension. In the Arctic, differences in the halosteric signal (not shown), due to differences in the oceanic response to precipitation, evaporation, runoff, and sea ice melt, explain most of the spread. In the Gulf Stream extension it is probably due to model errors and biases resulting from a misrepresentation of the Gulf Stream position and the coarse resolution of coupled CMIP5 models that do not adequately resolve regional dynamics (Saba et al. 2016).

\section{b. Contribution from atmospheric pressure loading}

Sea level responds to changes in atmospheric pressure loading generated by changes in the atmospheric circulation and the atmospheric moisture content (Wunsch and Stammer 1997; Stammer and Hüttemann 2008). The sea level response is not uniform as the changes in the atmospheric mass and pressure distribution are not uniform. To account for this effect, we estimate its contribution to regional sea level changes following Stammer and Hüttemann (2008). The atmospheric loading contribution is one order of magnitude smaller than the steric contribution (see Figs. 2a and S5) almost everywhere in the ocean. The ensemble mean of the atmospheric loading contribution shows a zonal distribution with the contribution being larger at the poles and slightly negative at middle and low latitudes (Fig. 2a). This response corresponds to the expected response to increasing GHG emissions [see Stammer and Hüttemann (2008) for more details]. Climate models agree on the contribution of the atmospheric loading to sea level changes in regions where the contribution is the largest: in the Southern Ocean (south of $35^{\circ} \mathrm{S}$ ) and in a zonal band between $60^{\circ}$ and $80^{\circ} \mathrm{N}$. In other regions the contribution is very small (see Fig. 2b).

\section{Contributions to twentieth-century sea level changes from mass transfers between land and ocean and from the solid Earth response}

In addition to ocean and atmospheric circulation changes, water mass transfers at Earth's surface can give rise to regional sea level change. The redistribution of mass perturbs Earth's gravitational field, deforms Earth's crust (also perturbing the gravitational field), and changes the orientation and rate of Earth's rotation (Mitrovica et al. 2001). In turn, these three processes affect the relative regional sea level (with respect to the solid Earth) and make it deviate substantially from the global mean sea level (Gomez et al. 2010; Milne et al. 2009; Mitrovica et al. 2009; Tamisiea and Mitrovica 2011). Note that the freshwater fluxes into the ocean associated with mass transfers between land and ocean change the ocean circulation and also generate regional variability in sea level (Kopp et al. 2009; Stammer 2008; Stammer et al. 2011; Lenaerts et al. 2015). This last 

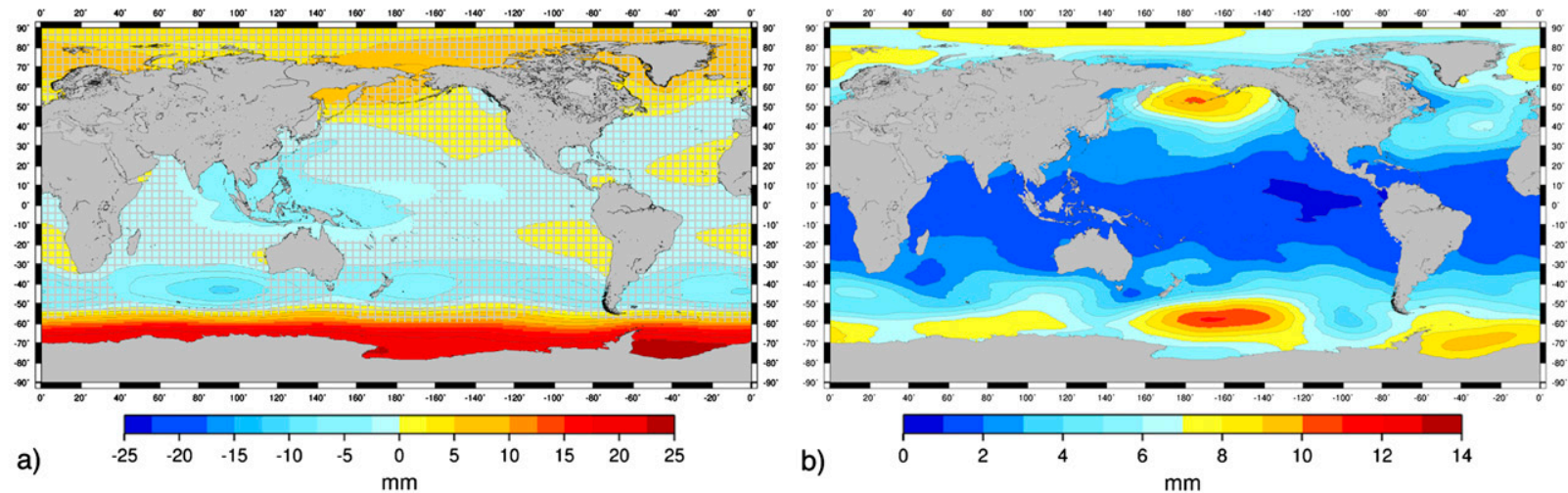

a)

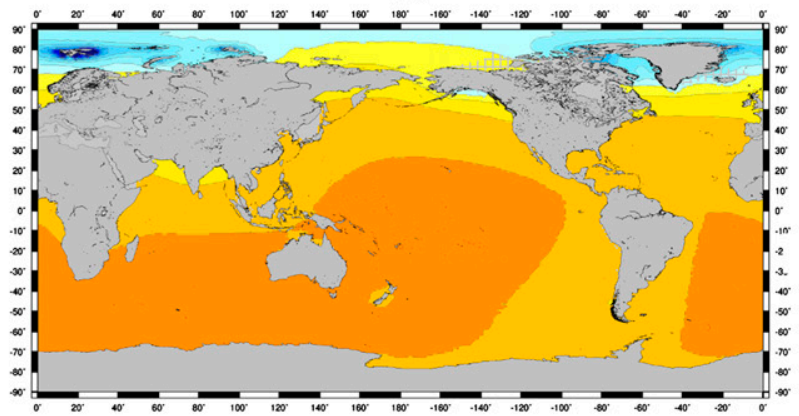

c)
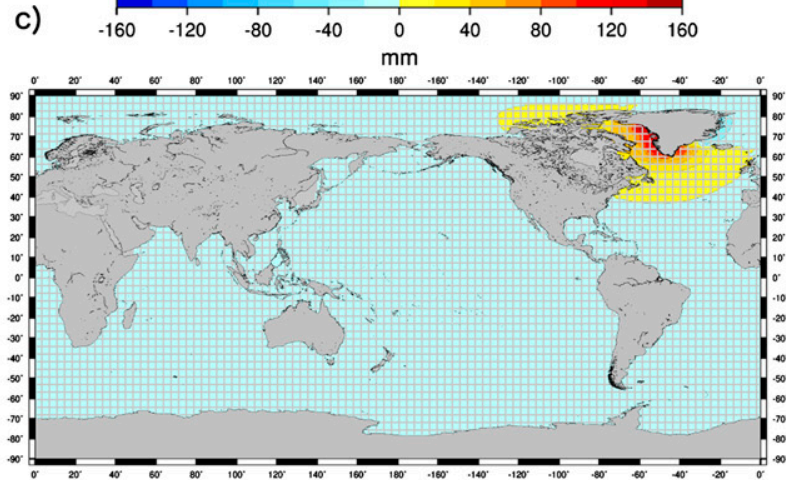

e)

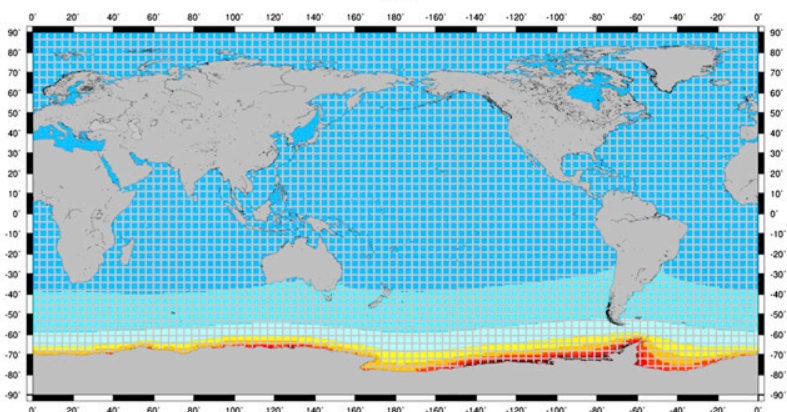

g)
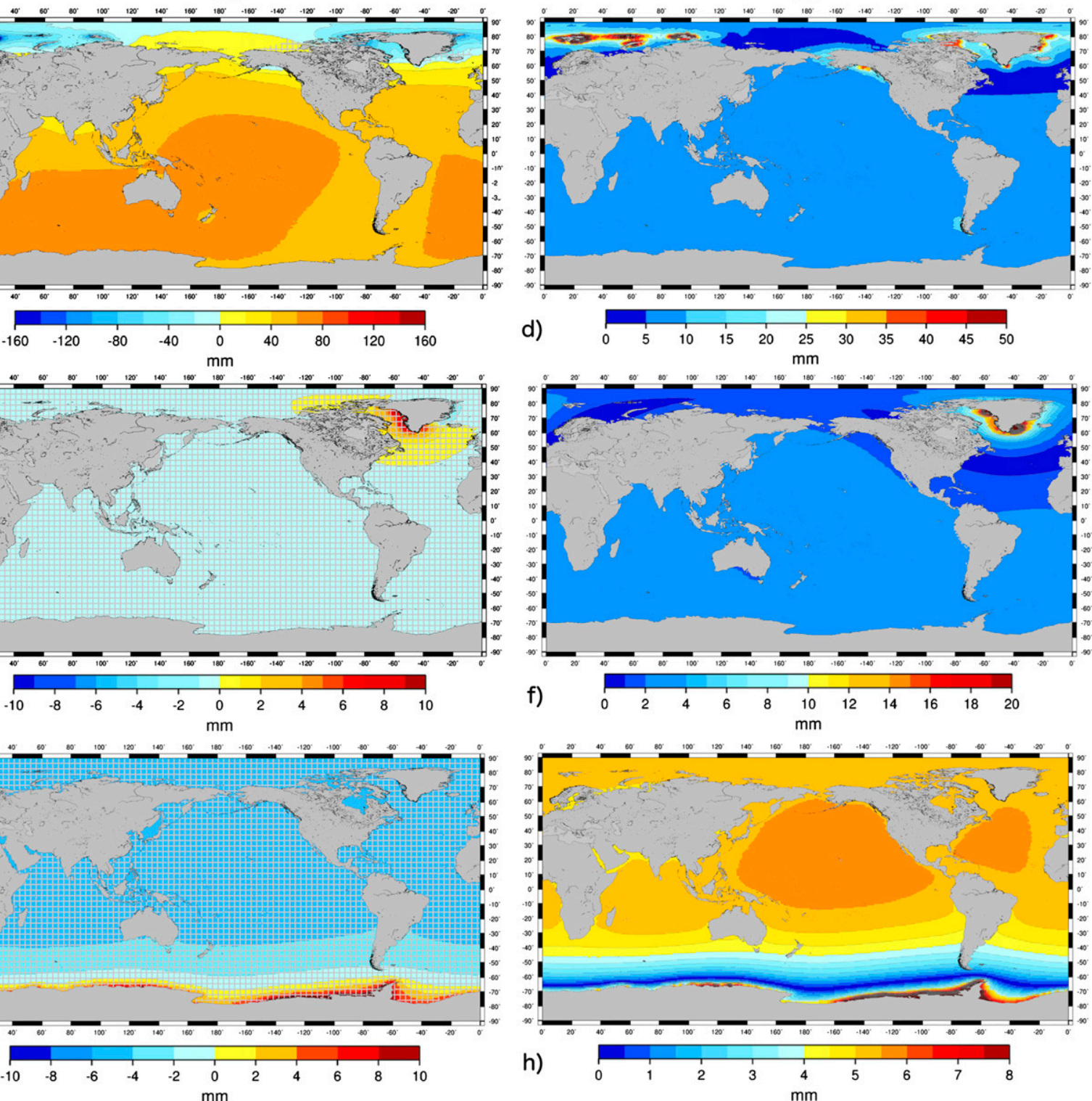

d)
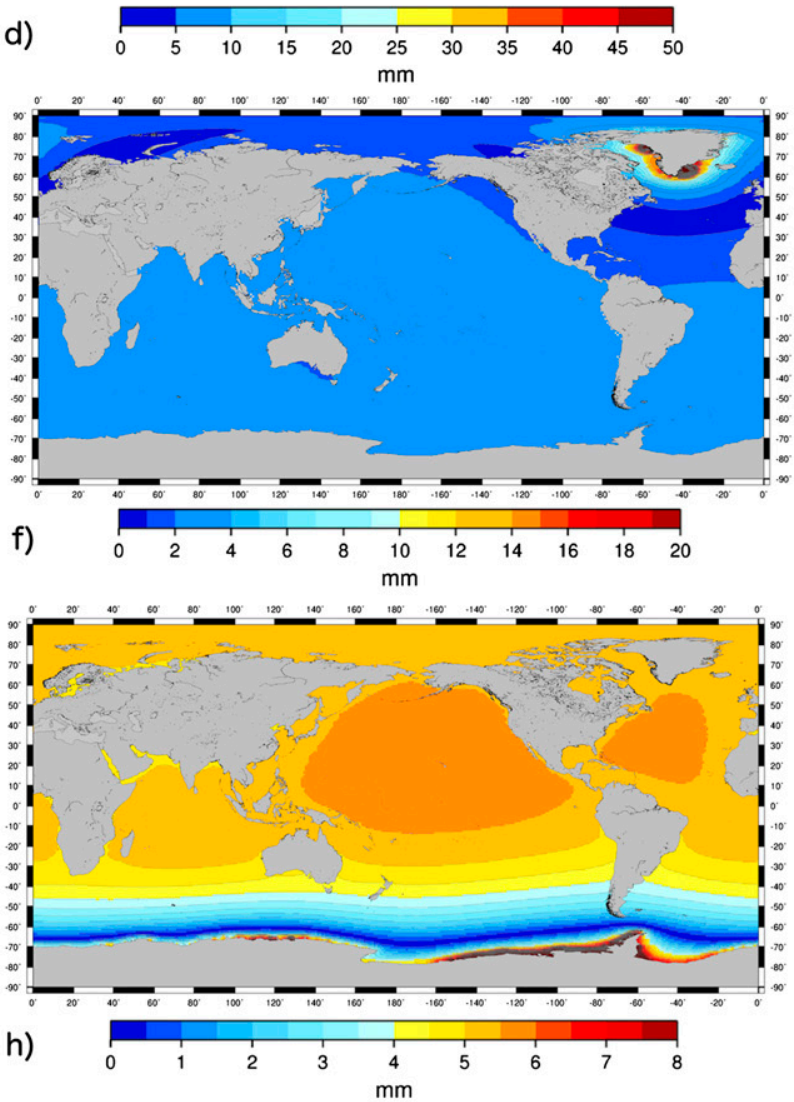

FIG. 2. (left) Ensemble mean of the (a) time-averaged atmospheric pressure loading contribution, (c) glaciers' mass change contribution, (e) Greenland SMB contribution, and (g) Antarctic SMB contribution to sea level for the period 1996-2015 relative to the reference period 1901-1920 (mm) (right) As at left, but for the respective RMS spread of the individual model result around the ensemble mean $(\mathrm{mm})$. At left, red indicates sea level rise and blue indicates sea level fall. The hatched areas indicate regions where the ensemble mean signal is smaller than 1.65 standard deviations of the ensemble spread (i.e., the $90 \% \mathrm{CL}$ ). 
aspect, however, is not addressed here as its effect on the dynamical sea level is likely negligible over the twentieth century given the small rates of freshwater fluxes into the ocean (the sum of all anomalies in freshwater fluxes into the ocean amounts to $\sim 1 \mathrm{~mm} \mathrm{yr}^{-1}$ sea level equivalent since 1900; see Gregory et al. 2013a). There is also a small contribution to geoid changes from the redistribution of ocean mass (as estimated in Fig. 1e). But this contribution is negligible (Gregory et al. 2013b), and we did not take it into account here.

Over the twentieth century there are essentially five sources of water mass transfer between land and ocean (Gregory et al. 2013a): glacier mass change, ice sheet SMB changes, changes in the dynamical ice flow from the ice sheets to the ocean, groundwater depletion, and reservoir storage changes. We estimate the mass transfers caused by glacier mass change and ice sheet SMB from climate model output (see sections $3 a$ and $3 b$ ). The mass transfers caused by ice sheet dynamics, groundwater depletion, and reservoir storage changes are not represented in climate models and are therefore estimated from observations. From the mass transfer estimates, we compute the regional sea level change pattern over the twentieth century using two different sea level equation solvers to give some indication of the uncertainty in the solid Earth response (including gravitational and rotational effects) to mass transfers. The first sea level equation solver is an updated version (Spada et al. 2012) of the solver SELEN [see Spada and Stocchi (2007) for details]. The second one is based on Schotman (2008) and solves the sea level equation using a pseudospectral approach (Farrell and Clark 1976; Schotman and Vermeersen 2005; Mitrovica and Peltier 1991). Both solvers assume a radially stratified and compressible Earth structure based on the Preliminary Reference Earth Model of Dziewonski and Anderson (1981) and include the effects of Earth rotation (Milne and Mitrovica 1998).

\section{a. Contribution from glacier mass change}

The twentieth-century glacier mass change is estimated by driving the global glacier evolution model of Marzeion et al. (2012a) with temperature and precipitation from the extended historical simulations of the CMIP5 climate models. It determines the mass balance change of all individual glaciers (excluding Antarctic peripheral glaciers) in the Randolph Glacier Inventory v4.0 (Arendt et al. 2014) from 1900 to 2015 and uses a simple parameterization of ice dynamics to calculate glacier hypsometry change (Marzeion et al. 2012b).

In previous studies (Cogley 2009; Marzeion et al. 2015), the same glacier model was forced with observations of temperature and precipitation and validated against both annual surface mass balance observations and observed accumulated volume changes of hundreds of glaciers. It was also forced with historical simulations of CMIP5 climate models (as in this study; Marzeion et al. 2012b, 2014b) to reconstruct past global glacier mass change (since 1851) that were a result of radiative forcing changes and compared with observations over the twentieth century. The simulated global glacier mass change model results, forced with CMIP5 historical experiments, are generally consistent with observations, except before 1950 when it is less positive than the observations (Church et al. 2013a,b; Marzeion et al. 2014a; Part I). This difference is caused by the mass balance of the Svalbard and Russian Arctic glaciers, which are too negative compared to the observations (Marzeion et al. 2014a).

The ensemble mean sea level change pattern associated with the twentieth-century glacier mass change (see Fig. 2c) shows a general sea level rise between 1901-20 and 1996-2015 except in the Arctic and close to Alaska. This pattern is confirmed by each individual model (see Figs. 2d and S6). The entire sea level pattern is a result of the water mass added to the ocean and the geoid changes in response to glacier mass loss (plus a contribution of the elastic rebound of the local Earth crust). South of $70^{\circ} \mathrm{N}$, the sea level rise signal is dominated by the ocean mass increase term while the sea level fall north of $70^{\circ} \mathrm{N}$ is mainly a response to the decrease in the local geoid height due to large mass loss of glaciers in Alaska, Svalbard, and the Russian Arctic since 1900.

The widespread retreat of glaciers started around the middle of the nineteenth century, at the end of the Little Ice Age (Leclercq et al. 2011). At this time, glacier mass change was dominated by the loss of ice at low altitudes as glaciers retreated from their nineteenth-century maxima (Marzeion et al. 2014b). During the second half of the twentieth century the forced response to anthropogenic GHG emissions accounts for the majority of glacier mass loss (Marzeion et al. 2014a; Slangen et al. 2016). The response of glaciers to the end of the Little Ice Age and the onset of GHG emissions is similar among models because they depend essentially on the state of glaciers during the initialization and the location of glaciers, which are both the same for all climate models. For this reason, the spread in sea level rise from glacier mass change is small among climate models (Fig. 2d). Note that our estimates do not include any allowance for glaciers that may have already disappeared or are now so small that they are inadequately represented in the glacier inventory. In addition there is an uncertainty in the response of glaciers to the Little Ice Age and the onset of GHG emissions that could be 
determined by considering different glacier models. But it was not possible here as Marzeion et al. (2012a)'s model is the only one available that give estimates of the twentieth-century glacier mass loss to date. As a result our uncertainty in glacier mass loss is likely underestimated. In the Arctic and close to Alaska, although ensemble members generally agree on showing a fall in sea level (see Fig. 2d), this fall is potentially systematically overestimated as the glacier mass loss is probably overestimated in this region (Marzeion et al. 2014a).

\section{b. Contribution from the Greenland ice sheet $S M B$}

The twentieth-century Greenland SMB is estimated with a downscaling technique based on the simulations of the regional climate model Modèle Atmosphérique Régional (MAR) version 3.5 forced with temperature and precipitation over the Greenland ice sheet from the extended historical simulations of CMIP5 climate models (Meyssignac et al. 2017a). The downscaling technique provides an estimate of the Greenland SMB at regional scale (over each of the six major drainage systems of the Greenland ice sheet) to take into account the nonuniform response of the Greenland SMB changes to GHG emissions (Tedesco and Fettweis 2012; Meyssignac et al. 2017a). The downscaling technique has been calibrated against the MAR simulations of the twentieth- and twenty-first-century Greenland ice sheet climate (Fettweis et al. 2013a) and validated by comparison with observations over the twentieth century (Meyssignac et al. 2017a).

Between 1901-20 and 1996-2015, the regional sea level change associated with Greenland SMB changes as estimated from the extended historical simulations of climate models is smaller than the one associated with glacier mass change by one order of magnitude (see Figs. 2e,f). In most of the ocean it amounts to about $-1 \pm 7 \mathrm{~mm}$. Close to the ice sheet, the signal increases to $\sim+8 \pm 15 \mathrm{~mm}$ due to increased gravitational attraction but it remains small compared to the local glacier contributions. The regional variability in the sea level signal around Greenland (with a positive signal to the south and west of Greenland and a negative signal to the north and east of Greenland; Fig. 2e) is caused by the regional variability in Greenland SMB (Meyssignac et al. 2017a).

Observation-based estimates and reanalysis-based estimates of Greenland SMB indicate a contribution of Greenland SMB to global sea level change of up to $25 \pm$ $9 \mathrm{~mm}$ and $10 \pm 4 \mathrm{~mm}$, respectively (Kjeldsen et al. 2015; Part I), which is significantly larger than the estimate based on extended historical simulations from climate models. The reason for the difference with observations is likely internal variability leading to more warming around Greenland in 1920-50 that is not present in the
CMIP5 model historical simulations (Church et al. 2013a; Part I). In general, extended historical simulations suggest that the signal from the Greenland SMB change is likely dominated by the internal variability of the climate system over the twentieth century as the spread between climate models is much larger than the signal in the ensemble mean (see Figs. 2e,d and S7).

It should be noted that a significant surface mass loss has been observed over Greenland from the end of the 1990s as a result of circulation changes in summer favoring advection of warm air over Greenland (Fettweis et al. 2013b). However, as shown by Fettweis et al. (2013b), these circulation changes are associated with a succession of negative North Atlantic Oscillation phases during 2007-12 that are not simulated by the CMIP5 models. Therefore, the CMIP5-based reconstruction underestimates the recent observed surface melt increase (Fettweis et al. 2013a; Meyssignac et al. 2017a). For this reason, together with the early twentiethcentury warming, it is likely that the actual twentiethcentury sea level contribution from the Greenland SMB is rather a small sea level rise than a small sea level fall as in Fig. 2e.

\section{c. Contribution from the Antarctic ice sheet $S M B$}

The Antarctic ice sheet SMB contribution is estimated at continental scale with two methods. First, we approximate the change in Antarctic SMB by taking the change in CMIP5 precipitation minus evaporation over the Antarctic ice sheet. Runoff of surface meltwater is neglected as it is very small under the present-day climate (Lenaerts et al. 2012). This approach relies directly on the CMIP5 model output although snowpack processes over the ice sheets are usually not correctly modeled in CMIP5 models. However, this is mainly an issue for the evaporation term but the evaporation averaged over the Antarctic ice sheet is generally an order of magnitude smaller than the precipitation (Lenaerts et al. 2012). The resulting SMB time series are scaled to fit the best estimate of the Antarctic SMB for the period 1985-2010 (merging historical and RCP8.5 experiments to go beyond 2005), from regional climate model RACMO2.1 forced by ERA-Interim reanalysis data (Lenaerts et al. 2012). We tested a second method to estimate the Antarctic SMB contribution to sea level, which accounts for the fact that the percentage change in SMB varies linearly with Antarctic surface temperature as shown by observations, paleosimulations, and projections of the future climate (Frieler et al. 2015). This increase in Antarctic SMB is due to an increase in precipitation as a result of the higher moisture holding capacity of warmer air (Church et al. 2013b). Following Frieler et al. (2015), we consider a continental-scale 
increase in snowfall of approximately $6 \% \pm 0.7 \% \mathrm{~K}^{-1}$ [90\% CL assuming a Gaussian distribution from Frieler et al. (2015)], which is consistent with observations of the last deglaciation based on ice core data. Both methods yield similar results over the twentieth century (see Part I) and indicate a small Antarctic SMB increase between 1901-20 and 1996-2015, equivalent to a sea level change of $-4 \pm 6 \mathrm{~mm}$ (again, see Part I).

The spatial pattern of the Antarctic SMB changes is assumed to be constant over 1900-2005. We compute an estimate of this pattern by averaging over 1979-2015 the Antarctic SMB calculated by the regional climate model RACMO (van Wessem et al. 2014) forced with ERAInterim (Dee et al. 2011). For each climate model run of our ensemble, we compute the regional Antarctic SMB changes by scaling the Antarctic SMB pattern with the total Antarctic SMB change computed from the precipitation and evaporation model outputs. The resulting ensemble mean sea level change pattern (Figs. 2g,h) indicates a global sea level fall except close to the ice sheet because gravitational pull increases as a result of the mass increase on the ice sheet (Fig. 2g). All models (except IPSL-CM5A-LR) show a small global sea level fall (Figs. $2 \mathrm{~h}$ and S8) of the same order of magnitude as the sea level fall due to Greenland SMB changes.

\section{d. Contribution from ice sheet dynamics, GIA, groundwater depletion, and reservoir storage changes}

In addition to steric sea level changes, pressure loading changes, glacier mass change, and ice sheet SMB changes, other processes that are not simulated by CMIP5 models can influence regional sea level changes: ice sheet dynamical processes (Katsman et al. 2011; Slangen et al. 2014a; Shepherd et al. 2012), long-term GIA (Peltier et al. 2015; Lambeck et al. 2010), and terrestrial water storage changes resulting from groundwater extraction (Wada et al. 2016; Döll et al. 2014; Konikow 2011) or reservoir construction (Chao et al. 2008). The impact of these processes on the twentiethcentury regional sea level changes is estimated here with observations or with offline models forced with observations.

Dynamical ice sheet changes gave rise to an increase in mass loss at the end of the twentieth century at its coastal margins via the acceleration in the flow of outlet glaciers. This acceleration occurred through a range of processes. On Greenland, the calving and melt of marine-terminating glaciers (e.g., Sundal et al. 2013) are the main mechanisms that cause an increase in ice flow velocity. On Antarctica, thinning (e.g., Pritchard et al. 2012) and breaking up (e.g., Cook and Vaughan 2010) of ice shelves that fringe the ice sheet result in a loss of buttressing strength on the flow of grounded ice. The understanding of ice sheet dynamical processes has improved recently (Schoof 2007; Joughin et al. 2014; Cornford et al. 2015) but modeling is still challenging and CMIP5 climate models do not include these processes. Here we use an estimate of the ice sheet dynamical contribution to sea level rise from 1992 to 2011 by Shepherd et al. (2012), following Part I. The total ice sheet mass balance estimate is available from 1993 to 2010 in four regions: West Antarctica, East Antarctica, the Antarctic Peninsula, and Greenland. The ice dynamical estimate is computed by removing the SMB (Shepherd et al. 2012) from the total ice sheet mass balance estimate. The ice dynamical time series are then extended to 2015 using the assumption that the West Antarctic discharge was slightly above the 2008-12 average (Sutterley et al. 2014), the East Antarctic and Antarctic Peninsula discharge followed the 2001-10 average, and the Greenland ice sheet discharge was constant at the 2010 value (Enderlin et al. 2014). Before 1993 we assume a constant dynamical contribution from both ice sheets. The constant contribution is estimated following Gregory et al. (2013a). It is computed as the opposite of the mean Antarctic and Greenland SMB over the period 1971-90 as both ice sheets are assumed to be close to mass balance during this period (Rignot et al. 2008; Hanna et al. 2011; Gregory et al. 2013a). The resulting contribution of ice sheet dynamics mass loss to the twentieth century sea level change is small $(7 \pm 5 \mathrm{~mm}$ at global scale; Part I) and the associated pattern with its uncertainty is shown in Figs. 3a and 3b. The pattern shows a sea level fall around Greenland and the western Antarctic ice sheet and a slight sea level rise close to the eastern Antarctic ice sheet. This regional variability in sea level is essentially caused by the changes in the local geoid in response to mass loss in Greenland and western Antarctica and mass gain in eastern Antarctica.

To account for the GIA of the solid Earth to the ice melt during the last deglaciation, we use the sea level change pattern from model outputs of Peltier (2004) and A et al. (2013). Both models use the ICE-5G ice chronology (VM2). They include the feedback on sea level caused by Earth rotation, and they use relative sea level observations and modern geodetic data to constrain their solutions. Peltier's (2004) model is based on a 1D model for the Earth's rheology, and it solves the sea level equation by traditional analytical methods. The model of A et al. (2013) is based on a 3D rheology model that takes into account the mantle heterogeneities on the GIA response, and it solves the sea level equation by a finite elements method. The use of these two GIA models enables the evaluation of the uncertainty associated with the Earth rheology representation and the 

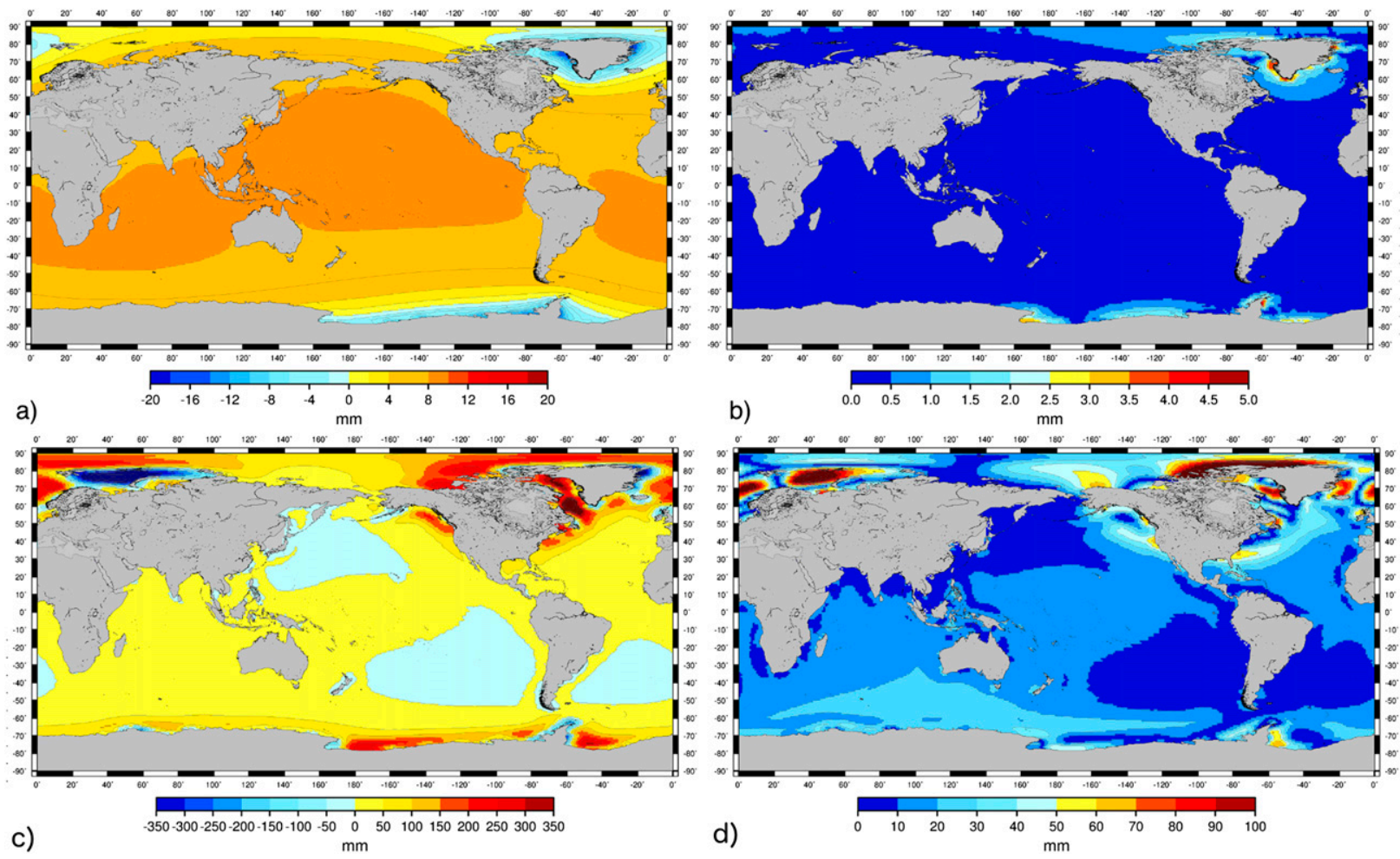

FIG. 3. (a) Mean of the time-averaged ice sheet dynamics contribution to sea level for the period 1996-2015 relative to the reference period 1901-20 (mm) computed with the two sea level equation solvers (see text). (b) RMS spread of the individual sea level equation solver results around the mean (mm). (c) Mean of the Peltier (2004) and A et al. (2013) estimates of the time-averaged GIA contribution to sea level for the period 1996-2015 relative to the reference period 1901-20 (mm). (d) RMS spread of the individual estimate of the GIA contribution around the mean ( $\mathrm{mm})$. In (a) and (c) red indicates sea level rise and blue indicates sea level fall.

sea level equation solver method, but it does not enable the evaluation of the uncertainty associated with the deglaciation history. Figure $3 \mathrm{c}$ shows the sea level pattern obtained from a mean of Peltier (2004) and A et al. (2013). This sea level pattern is characterized by regions of large sea level fall (down to $-200 \mathrm{~mm}$ ) in formerly glaciated regions due to land uplift (around Greenland, Antarctica, Fennoscandia, and Laurentide) and large sea level rise (up to $+300 \mathrm{~mm}$ ) in forebulge regions [for further details, see, e.g., Tamisiea (2011)]. Figure 3d shows the 1.65 standard deviation between the two GIA model estimates of the sea level patterns. Most of the differences are observed in the Arctic Ocean along the coast.

Climate variability and direct human interventions can change the land water storage and impact sea level. Natural climate variability changes the amount of water stored in lakes, rivers aquifers, and soil moisture. On interannual time scales these changes can be substantial (up to a few millimeters per year; Cazenave et al. 2012; Boening et al. 2012; Fasullo et al. 2013) but at decadal and longer time scales this contribution is small (Ngo-Duc et al. 2005) and we therefore neglect it here.
However, direct human interventions such as the building of reservoirs (Chao et al. 2008) and the depletion of groundwater (Konikow 2011; Wada et al. $2012,2016)$ cause sizeable contributions to twentiethcentury sea level changes. For reservoir storage we use the estimate of Chao et al. (2008) with no allowance for seepage [as in Gregory et al. (2013a)]. We also assume that the reservoirs are on average $85 \%$ full to correct for reduction of the storage capacity over time due to sedimentation as suggested in IPCC AR5 (Church et al. 2013b). For groundwater depletion we use the mean of two estimates: 1) the estimate from Wada et al. (2012) for 1900-2005, which has been corrected for recent findings in Wada et al. (2016), showing that only $80 \%$ of the depleted groundwater ends up in the ocean; and 2) the estimate from Döll et al. (2014), available from 1902 to 2009. The time series were all extended to 2015 using the average rate in the last 5 years of data.

Before 1950 both contributions from reservoirs and groundwater depletion are negligible $(<2 \mathrm{~mm})$ but after 1950 they become sizeable $(-25 \mathrm{~mm}$ from reservoir storage and $+13 \pm 3 \mathrm{~mm}$ for groundwater depletion). Following 1950, the contribution is negative because of 


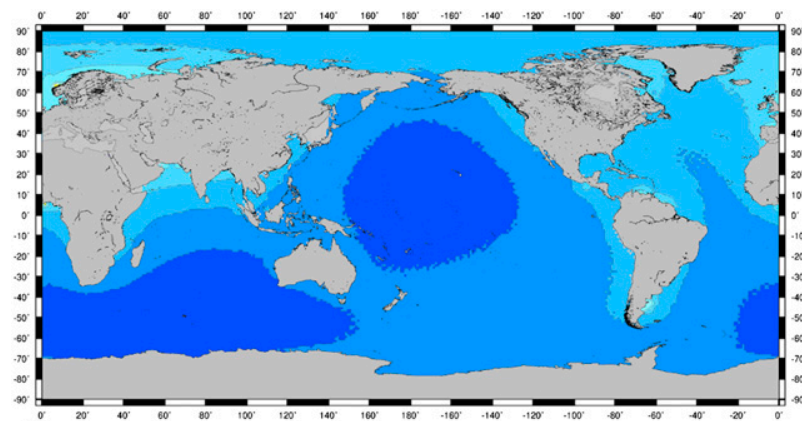

a)

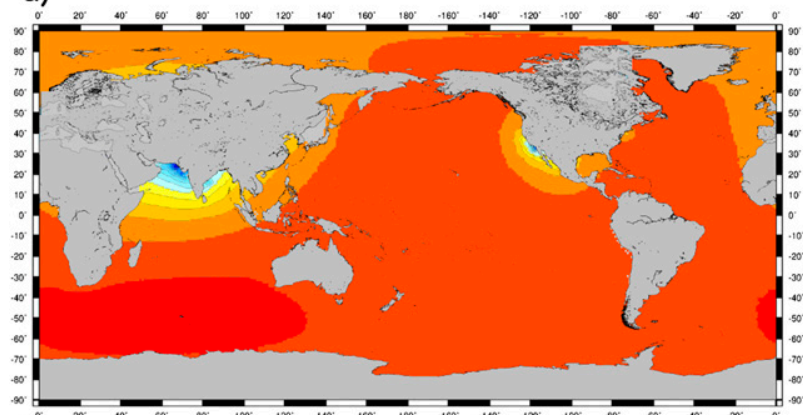

b)

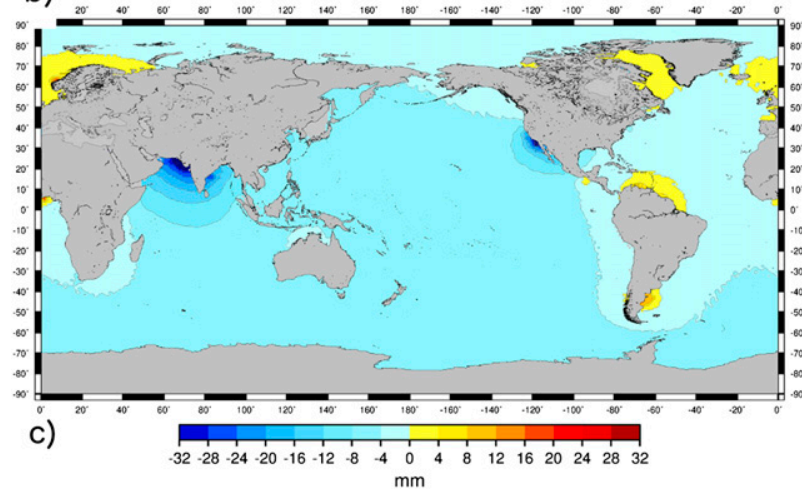

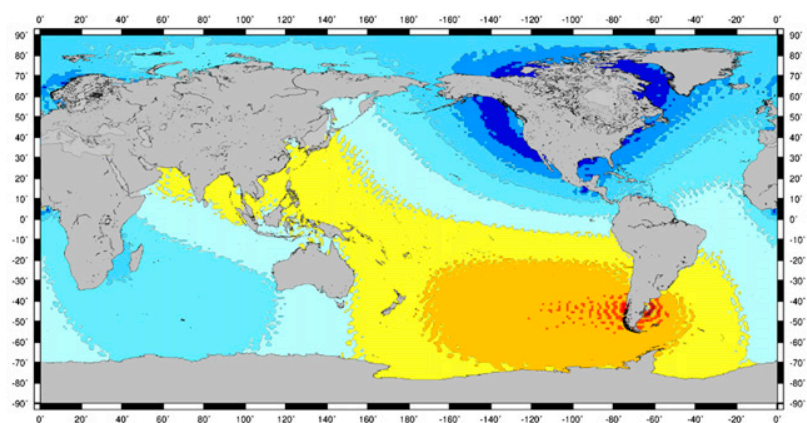

d)

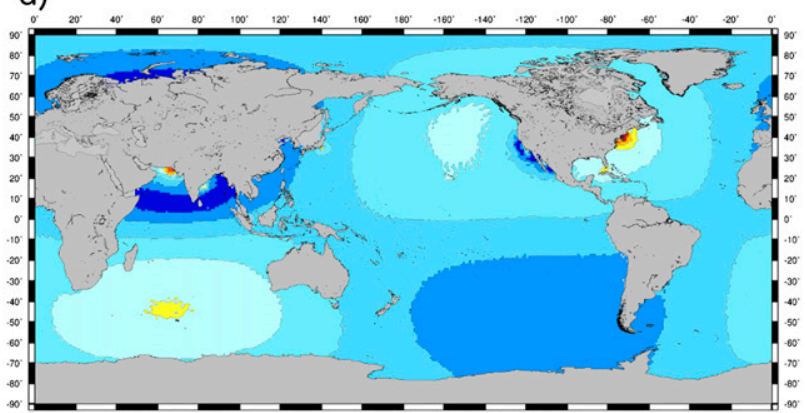

e)

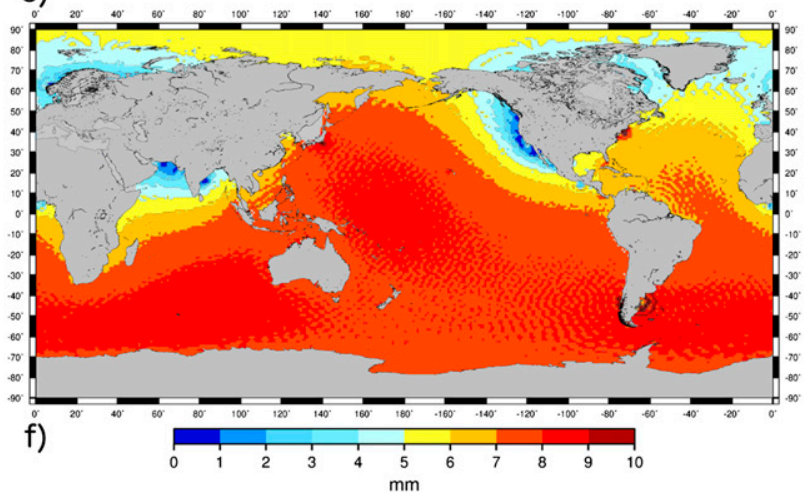

FIG. 4. Mean of the observation based estimate of (a) the surface reservoir contribution and (b) the groundwater depletion contribution to sea level for the period 1996-2015 relative to the reference period 1901-20 (mm) computed with the two sea level equation solvers (see text). (c) The total terrestrial water contribution (the sum of the surface reservoir contribution and the groundwater depletion contribution). Red indicates regions of sea level rise and blue indicates regions of sea level fall. (d)-(f) As in (a)-(c), but for RMS spread of the individual sea level equation solver results around the mean $(\mathrm{mm})$.

the increase in the rate of dam building, and it becomes positive after the 1980s because of the slowing in the rate of dam building and the increase in the rate of groundwater depletion. Figures $4 \mathrm{e}$ and $4 \mathrm{f}$ show the associated pattern in sea level change between 1901-20 and 19962015 and its uncertainty. The pattern is consistent with the pattern found by Fiedler and Conrad (2010) and Veit and Conrad (2016). It shows a global sea level fall because of the dominant effect of the increase in the rate of dam building over the second half of the twentieth century (Figs. 4a,b). The sea level rise patterns around North America and Europe are caused by the local geoid increase and a change in the ocean floor due to the loading and unloading of the water mass stored behind dams in these regions since 1950. The sea level fall patterns observed around India and California are due to the decrease of the local geoid in response to the extraction of groundwater in these regions at the end of the twentieth century (Figs. 4c,d).

\section{Comparison of modeled twentieth-century sea level changes with tide gauge records}

\section{a. Total twentieth-century regional sea level changes} from climate models

We sum all the contributions to twentieth-century sea level changes and estimate the total ensemble mean and 

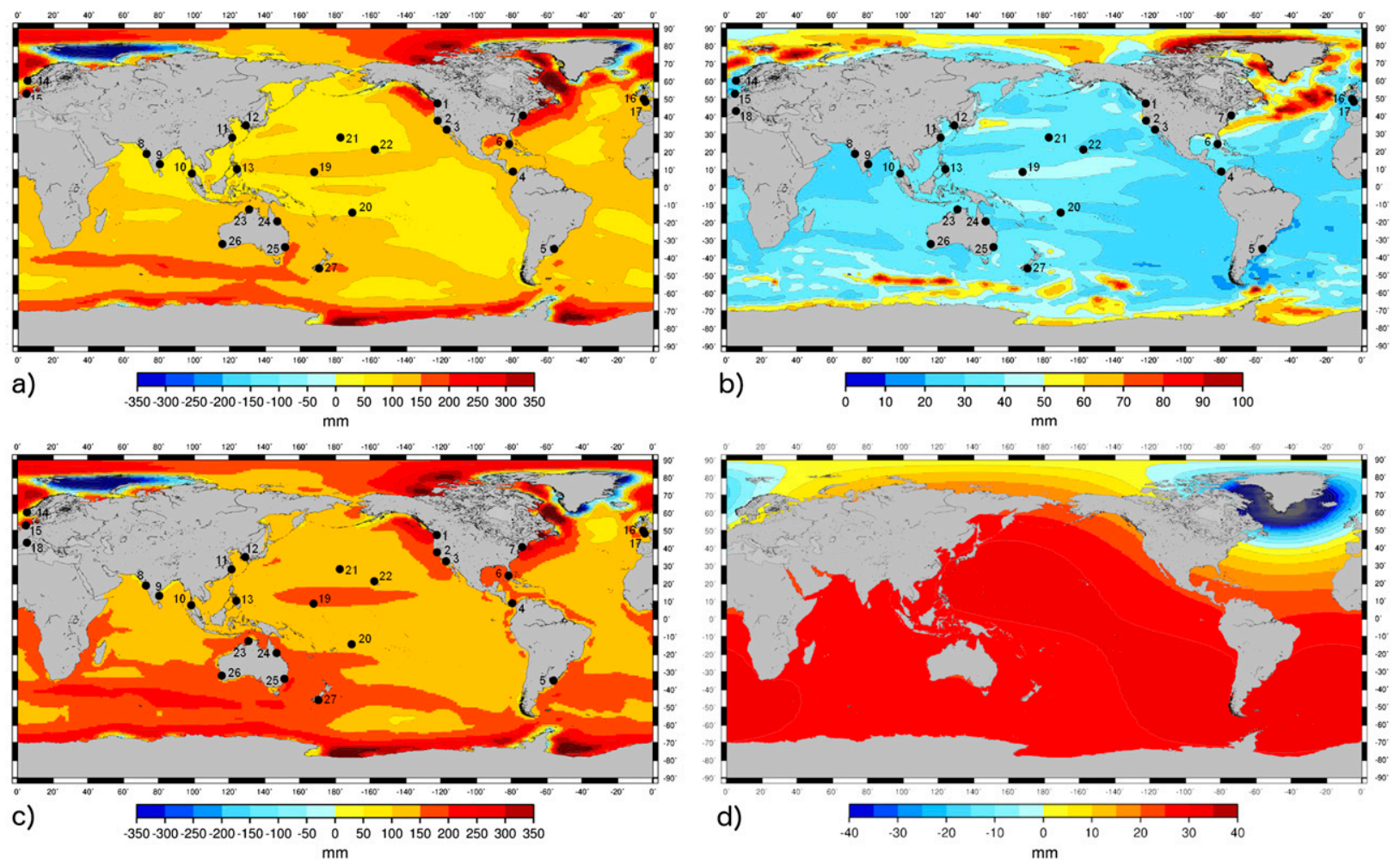

FIG. 5. (a) Ensemble mean of the time-averaged total relative sea level change for the period 1996-2015 relative to the reference period 1901-20 (mm). (b) RMS spread of the individual model result around the ensemble mean (mm). (c) Ensemble mean of the time-averaged total sea level for the period 1996-2015 relative to the reference period 1901-20 including the bias correction presented in (d) (mm). (d) Sea level change for the period 1996-2015 relative to the reference period 1901-20 induced by the ice sheets/deep ocean correction plus glaciers and Greenland SMB correction. The black dots in (a) and (c) indicate the position of the tide gauge records used to assess the simulated sea level from climate models. The numbers identify the tide gauge records plotted in Figs. 6-8. In (a) and (c) red indicates sea level rise and blue indicates sea level fall. The hatched areas indicate regions where the ensemble mean signal is smaller than 1.65 standard deviations of the ensemble spread (i.e., the $90 \% \mathrm{CL}$ ).

ensemble spread in regional relative sea level changes between 1901-20 and 1996-2015 from climate models (see Figs. 5 and S9). The regional sea level changes range from $\sim-68 \mathrm{~cm}$ in the Russian Arctic to $\sim+55 \mathrm{~cm}$ on the eastern coast of Canada. Spatial variations are dominated by the contribution from GIA and the steric sea level. The glacier mass change contribution is relatively large ( $54 \%$ of the global mean sea level; Part I) but its signature is nearly uniform except around Greenland, Svalbard, the Arctic, and Patagonia, where it generates a large sea level fall and dominates the sea level signal. The GIA contribution is larger around the locations of former ice sheets such as in the Southern Ocean close to the Antarctic coast or in the Arctic close to Svalbard. The spatial signatures of the other contributions are less obvious although they can be larger locally in many regions (such as the groundwater depletion contribution, which is sizeable around India) (see Fig. 4).

The spread among climate models in regional sea level rise is larger than the ensemble mean signal in the
North Atlantic and locally in the Southern Ocean (Fig. 1). In the rest of the ocean the spread is comparable to or smaller than the ensemble mean signal because the glacier mass change contribution, which is consistent among ensemble members, plays a significant role (see Figs. 2a,b).

\section{b. Observed regional sea level changes from tide gauge records}

We compare the estimated relative sea level changes from climate models with observations of 27 long tide gauge records distributed around the world (see Fig. 5a and Tables 2 and 3). The tide gauge records have been selected from the Permanent Service for Mean Sea Level (PSMSL 2016; Holgate et al. 2013) on quality, length, and localization criteria with the objective to get the longest high-quality tide gauge dataset covering all regions of the world. Most of the selected tide gauge records cover a period longer than 70 years. In regions where such long tide gauge records could not be found in 
TABLE 2. VLM rates at the 27 tide gauge sites derived from GPS measurement and the Peltier (2004) GIA model. Negative values denote subsidence. The error on GPS VLM land motion is obtained from Santamaría-Gómez et al. (2012).

\begin{tabular}{|c|c|c|c|c|c|c|}
\hline \multirow[b]{2}{*}{$\begin{array}{l}\text { Tide gauge } \\
\text { station name } \\
\text { (as in PSMSL) }\end{array}$} & \multicolumn{4}{|c|}{ VLM from GPS receivers } & \multirow[b]{2}{*}{$\begin{array}{l}\text { GIA } \\
\text { VLM }\end{array}$} & \multirow[b]{2}{*}{$\begin{array}{l}\text { Inferred } \\
\text { non-GIA } \\
\text { VLM }\end{array}$} \\
\hline & $\begin{array}{c}\text { GPS } \\
\text { VLM } \\
\left(\mathrm{mm} \mathrm{yr}^{-1}\right)\end{array}$ & $\begin{array}{l}\text { GPS VLM } \\
\text { error } \\
\left(\mathrm{mm} \mathrm{yr}^{-1}\right)\end{array}$ & $\begin{array}{l}\text { Distance between the } \\
\text { GPS receiver and the } \\
\text { TG station }(\mathrm{m})\end{array}$ & $\begin{array}{c}\text { GPS } \\
\text { record } \\
\text { length }(\mathrm{yr})\end{array}$ & & \\
\hline Seattle & -0.99 & \pm 0.22 & 5900 & 15.9 & -1.07 & +0.08 \\
\hline \multirow[t]{3}{*}{ San Francisco } & -0.84 & \pm 0.21 & 6500 & 9.1 & -0.98 & +0.14 \\
\hline & -0.04 & \pm 0.15 & 9551 & 19.0 & & +0.94 \\
\hline & -0.51 & \pm 0.71 & 14235 & 8.0 & & +0.47 \\
\hline \multirow[t]{2}{*}{ San Diego } & -0.99 & \pm 0.32 & 8400 & 9.8 & -0.82 & -0.17 \\
\hline & -2.62 & \pm 0.19 & 8400 & 6.5 & & -1.80 \\
\hline Balboa & - & - & - & - & -0.26 & - \\
\hline Montevideo & - & - & - & - & +0.67 & - \\
\hline \multirow{3}{*}{ Key West } & +0.26 & \pm 0.43 & 15946 & 10.5 & -0.74 & +1.0 \\
\hline & -1.76 & \pm 0.43 & 15946 & 6.2 & & -1.02 \\
\hline & -1.07 & \pm 0.38 & 5424 & 10.7 & & -0.33 \\
\hline New York & -2.12 & \pm 0.62 & 49 & 3.2 & -1.75 & -0.37 \\
\hline Mumbai & - & - & - & - & +0.30 & - \\
\hline Chennai & - & - & - & - & +0.22 & - \\
\hline Ko Taphao Noi & - & - & - & - & +0.16 & - \\
\hline Cebu & - & - & - & - & +0.30 & - \\
\hline Kanmen & - & - & - & - & +0.45 & - \\
\hline Busan & - & - & - & - & +0.53 & - \\
\hline Darwin & -0.17 & \pm 0.85 & 7279 & 6.0 & -0.09 & -0.08 \\
\hline Townsville & -0.54 & \pm 0.21 & 930 & 18.6 & -0.11 & -0.43 \\
\hline Fort Denison & -0.33 & \pm 0.25 & 10775 & 8.6 & -0.22 & -0.11 \\
\hline \multirow[t]{2}{*}{ Dunedin } & -1.02 & \pm 0.12 & 2 & 12.1 & -0.02 & -1.0 \\
\hline & -1.71 & \pm 0.18 & 8115 & 8.3 & & -1.69 \\
\hline Fremantle & - & - & - & - & -0.33 & - \\
\hline Bergen & - & - & - & - & -1.76 & - \\
\hline Den Helder & - & - & - & - & -0.53 & - \\
\hline Newlyn & -0.17 & \pm 0.14 & 5 & 15.2 & -0.62 & +0.45 \\
\hline \multirow[t]{2}{*}{ Brest } & 0.01 & \pm 0.11 & 293 & 15.2 & -0.59 & +0.60 \\
\hline & -0.49 & \pm 0.15 & 9213 & 11.2 & & +0.10 \\
\hline \multirow[t]{2}{*}{ Marseille } & -0.18 & \pm 0.19 & 5 & 15.4 & -0.32 & +0.14 \\
\hline & -0.42 & \pm 0.41 & 1544 & 6.4 & & -0.10 \\
\hline \multirow[t]{2}{*}{ Honolulu } & -0.23 & \pm 0.18 & 1 & 16.0 & -0.17 & -0.06 \\
\hline & -0.62 & \pm 0.3 & 5935 & 10.8 & & -0.45 \\
\hline Midway Island & - & - & - & - & -0.06 & - \\
\hline Kwajalein & +0.48 & \pm 0.38 & 1175 & 6.4 & -0.10 & +0.58 \\
\hline Pago Pago & - & - & - & - & -0.14 & - \\
\hline
\end{tabular}

the PSMSL, the longest one available was chosen. We use annual mean revised local reference tide gauge records (i.e., with benchmarks controlled by regular leveling). The gaps in tide gauge records are not filled.

Tide gauges need to be corrected for vertical land movement (VLM) processes other than GIA, which is included in the projections. These processes include tectonics, sediment compaction, or subsidence caused by anthropogenic extraction of underground fluids. The associated vertical movements can be estimated with GPS measurements (Wöppelmann et al. 2009). Considerable efforts are being undertaken worldwide to equip tide gauges with collocated GPS receivers. However, the number of collocated tide gauge stations and
GPS receivers is still limited. For some nonequipped stations, GPS receivers can be found close by. But in general, geodetic connections between the tide gauge stations and the nearest GPS receivers are often missing, which raises the question whether the nearby measured VLM represents the exact motion at the tide gauge (Wöppelmann and Marcos 2012). Furthermore GPS records are often short (covering the past one to two decades) and contain substantial noise. Thus, VLM rates cannot be determined to the required degree of accuracy (i.e., a few tenths of a millimeter per year here; Wöppelmann et al. 2009) for all selected tide gauge records. Here, we use VLM estimates derived from the latest GPS solution (ULR6; Santamaría-Gómez et al. 
TABLE 3. RMS ( $\mathrm{mm}$ ) of the 27 detrended tide gauge records and RMS( $\mathrm{mm}$ ) of collocated climate model control run time series. The RMS of climate model time series are computed over the same period as the period spanned by the tide gauge records. They are computed from the control runs of the 12 climate models of Table 1 . The uncertainty is given with a $90 \%$ confidence level ( $1.65 \sigma$ assuming a Gaussian distribution). Bold numbers indicate places where the observed sea level RMS is out of the range of the modeled sea level RMS.

\begin{tabular}{|c|c|c|c|c|c|}
\hline $\begin{array}{c}\text { Tide gauge } \\
\text { station name } \\
\text { (as in PSMSL) }\end{array}$ & $\begin{array}{l}\text { Tide } \\
\text { gauge } \\
\text { No. }\end{array}$ & $\begin{array}{l}\text { RMS of the detrended } \\
\text { annual TG time } \\
\text { series }(\mathrm{mm})\end{array}$ & $\begin{array}{l}\text { RMS of the climate } \\
\text { model control run } \\
\text { annual time series }(\mathrm{mm})\end{array}$ & $\begin{array}{c}\text { RMS of the } \\
\text { detrended TG } \\
\text { time series }(\mathrm{mm})\end{array}$ & $\begin{array}{c}\text { RMS of the climate } \\
\text { model control run } \\
\text { decadal time series }(\mathrm{mm})\end{array}$ \\
\hline Seattle & 1 & 33.0 & $49.1 \pm 18$ & 17.5 & $23.5 \pm 14$ \\
\hline San Francisco & 2 & 36.5 & $40.6 \pm 36$ & 14.3 & $18.6 \pm 18$ \\
\hline San Diego & 3 & 29.3 & $48.2 \pm 26$ & 12.3 & $19.6 \pm 17$ \\
\hline Balboa & 4 & 40.3 & $44.6 \pm 38$ & 10.7 & $13.9 \pm 8$ \\
\hline Montevideo & 5 & 56.8 & $28.2 \pm 26$ & 19.2 & $18.8 \pm 14$ \\
\hline Key West & 6 & 25.0 & $39.0 \pm 35$ & 11.6 & $17.5 \pm 12$ \\
\hline New York & 7 & 30.1 & $58.6 \pm 29$ & 10.7 & $27.7 \pm 18$ \\
\hline Mumbai & 8 & 32.3 & $43.6 \pm 22$ & 26.5 & $14.7 \pm 12$ \\
\hline Chennai & 9 & 30.6 & $61.1 \pm 28$ & 8.8 & $28.5 \pm 21$ \\
\hline Ko Taphao Noi & 10 & 85.10 & $78.4 \pm 33$ & 48.7 & $28.0 \pm 14$ \\
\hline Cebu & 13 & 47.9 & $83.1 \pm 55$ & 45.7 & $24.6 \pm 23$ \\
\hline Kanmen & 11 & 26.2 & $78.8 \pm 40$ & 7.8 & $33.1 \pm 29$ \\
\hline Busan & 12 & 23.1 & $76.4 \pm 35$ & 9.6 & $26.5 \pm 21$ \\
\hline Darwin & 23 & 77.5 & $85.8 \pm 61$ & 23.2 & $22.1 \pm 22$ \\
\hline Townsville & 24 & 32.8 & $79.8 \pm 41$ & 3.6 & $31.4 \pm 29$ \\
\hline Fort Denison & 25 & 26.4 & $59.9 \pm 59$ & 15.6 & $34.3 \pm 26$ \\
\hline Dunedin & 27 & 36.5 & $57.0 \pm 24$ & 14.4 & $28.3 \pm 13$ \\
\hline Fremantle & 26 & 49.9 & $61.1 \pm 51$ & 38.4 & $28.4 \pm 22$ \\
\hline Bergen & 14 & 34.4 & $64.7 \pm 16$ & 23.8 & $24.1 \pm 15$ \\
\hline Den Helder & 15 & 34.7 & $69.2 \pm 27$ & 16.0 & $19.9 \pm 11$ \\
\hline Newlyn & 16 & 26.2 & $46.0 \pm 38$ & 12.1 & $7.4 \pm 7$ \\
\hline Brest & 17 & 33.7 & $47.4 \pm 16$ & 20.2 & $15.4 \pm 15$ \\
\hline Marseille & 18 & 32.7 & $46.3 \pm 14$ & 20.8 & $22.9 \pm 9$ \\
\hline Honolulu & 21 & 34.7 & $26.6 \pm 9$ & 10.9 & $10.8 \pm 5$ \\
\hline Midway Island & 22 & 39.8 & $90.3 \pm 51$ & 25.1 & $47.5 \pm 32$ \\
\hline Kwajalein & 19 & 50.1 & $100.8 \pm 63$ & 23.8 & $37.8 \pm 21$ \\
\hline Pago Pago & 20 & 55.6 & $116.4 \pm 77$ & 15.7 & $45.2 \pm 25$ \\
\hline
\end{tabular}

2012) of the SONEL group (www.sonel.org). We only considered VLM estimates from GPS receivers that are within $16 \mathrm{~km}$ from the tide gauge stations. Considering these constraints, the ULR solution provides VLM estimates for 15 of the 27 tide-gauge records. Table 2 presents these estimates with the formal errors (taking into account the temporal correlation; SantamaríaGómez et al. 2012) along with additional information on the distance between the GPS receivers and the tide gauges and on the length of the GPS records. Table 2 also includes the GIA vertical motion at the tide gauge stations estimated from the GIA model. These GIA vertical motions are subtracted from the GPS VLM estimates to deduce the VLM correction associated to tectonics, sediment compaction and anthropogenic subsidence only. The latter correction is applied to the tide gauge records to correct for non-GIA vertical land motion. When several GPS VLM estimates are available for the same tide gauge station (like for San Francisco; see Table 2) we use the mean of all GPS VLM available to compute the VLM correction. In general, the VLM correction applied to the tide gauge records is small and on the order of a few tenths of a millimeter per year (see Table 2).

\section{c. Sea level estimates from climate models against observations from tide gauge records}

\section{1) IN THE AMERICAS}

Figure 6 shows the comparison between total annual simulated sea level and tide gauge records while Fig. 7 shows the comparison between detrended decadal simulated sea level and tide gauge records. In both figures, the blue curve represents the ensemble mean sea level estimate from climate models at the tide gauge location. It shows a much smaller interannual to multidecadal variability than the tide gauge records (black curve) because the internal variability being not necessarily in phase in climate model simulations averages out in the ensemble mean. The ensemble spread (blue shaded area; $1.65 \sigma ; 90 \% \mathrm{CL}$, assuming a Gaussian distribution) gives an estimate of the differences among modeled 

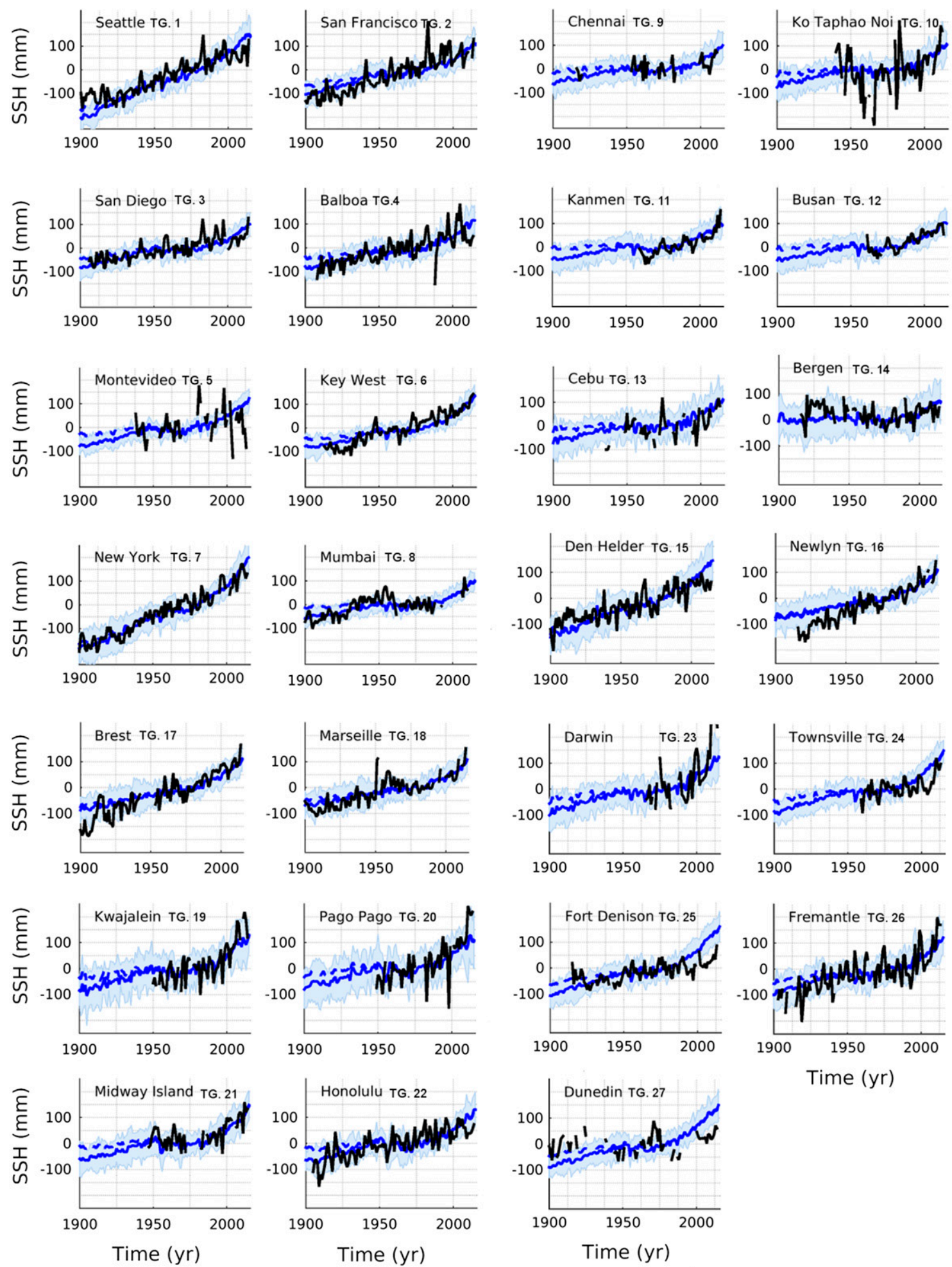

FIG. 6. Total simulated annual local sea level with (blue solid curve) and without (blue dotted curve) the correction (see text and Fig. 5) at tide gauge stations against tide gauge records (black curve). The shaded blue areas represent the ensemble spread ( $1.65 \sigma ;$ i.e., $90 \%$ CL, assuming a Gaussian distribution) of the simulated sea level. 

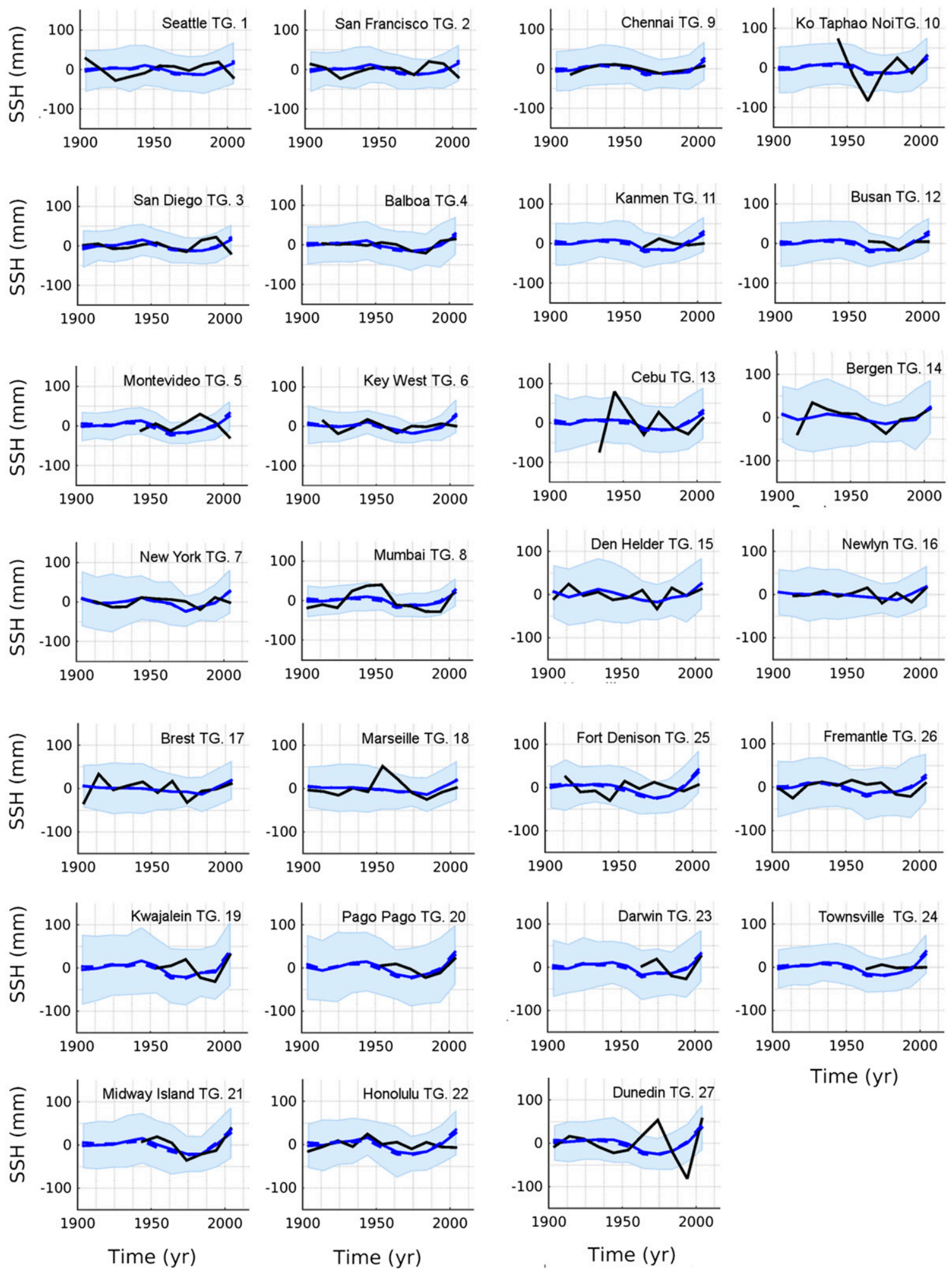

FIG. 7. Detrended total simulated decadal local sea level with (blue solid curve) and without (blue dotted curve) the correction (see text and Fig. 5) at tide gauge stations against detrended tide gauge records (black curve). The shaded blue areas represent the ensemble spread (1.65 ; i.e., $90 \%$ CL, assuming a Gaussian distribution) of the simulated sea level. Tide gauge records have been splined to fill the gaps where not enough data are available for the computation of decadal means. 
estimates of the local sea level at tide gauge locations. These differences come from differences in the effective forcing between climate model simulations, differences in the sensitivity to the forcing between climate models, and internal variability (Melet and Meyssignac 2015). For all American tide gauge records, except the Montevideo record, the interannual to decadal variability lies mostly within the shaded area (see Figs. 6 and 7 and Table 3), indicating a good agreement between the simulated sea level variability and the observations at these time scales. There are exceptions to this statement. In 1941 and 1983, the tide gauge records of the western North American coast (the Seattle, San Francisco, and San Diego tide gauge records) indicate an exceptionally high sea level associated with the extreme ENSO events of 1941 and 1983. These high sea levels are significantly outside the ensemble spread and suggest that climate models underestimate the interannual variability in sea level associated with such extreme ENSO events. This is probably due to an underestimate of the dynamic sea level response to wind stress as most of the sea level response along the western U.S. coast is caused by local wind stress anomalies and coastal trapped waves that are generated along the equator and propagate to the north along the coast during ENSO events (e.g., Ryan and Noble 2002; Roberts et al. 2016). Biases in precipitation patterns and terrestrial water storage changes associated with ENSO events could also generate biases in ocean mass changes during extreme ENSO events and explain part of the mismatch here. The Balboa record also shows an extreme sea level during the 1988 La Niña event, which is out of the range of the ensemble spread (Fig. 6). But it is unclear whether it is due to an underestimate of the local interannual variability by the simulated sea level or due to a datum anomaly in the tide gauge record following the data gap of 1987 (see the PSMSL documentation).

The Montevideo record shows consistently higher interannual variability than the simulated sea level since 1970. However, it is difficult to draw any conclusion from this because the Montevideo record is affected by the discharge of both the Parana and Uruguay Rivers, which is not taken into account in the simulated sea level.

In term of trends, there is agreement (at the $90 \% \mathrm{CL}$ ) between the simulated sea level and the tide gauge records in Seattle, San Diego, Key West, and New York (see Fig. 9a below). The modeled trend underestimates the observed trend in San Francisco and Balboa and overestimates it in Montevideo. The mismatch with the San Francisco tide gauge record is likely not caused by an underestimation of the simulated contributions to sea level in this region as no mismatch is found with the nearby tide gauge record of San Diego. We rather suspect a problem with the local VLM correction. Indeed, the longest GPS record located nearby the San Francisco tide gauge only covers the last 19 years and could have been affected by short-time-scale tectonics, which are not representative of the long-term local subsidence.

Close to the former ice sheets, in the north of the United States, like in Seattle and New York, the sea level trends are large $\left(\sim 3 \mathrm{~mm} \mathrm{yr}^{-1}\right)$ and dominated by the GIA contribution (Fig. 8). For the other American tide gauge records, which are located farther from the former ice sheets, the sea level trends are smaller $\left(\sim 1.5 \mathrm{~mm} \mathrm{yr}^{-1}\right)$ and dominated by the land ice and the dynamic sea level contributions.

\section{2) IN ASIA}

In Asia, the observed interannual variability is in general overestimated by the model results (see Table 3) while the multidecadal variability in sea level is fairly well captured by climate models (see Table 3 and Figs. 6 and 7) (except in the Andaman sea at Ko Taphao Noi). A consistent conclusion from a number of studies on the sea level variability in the Indian Ocean (e.g., Clarke and Liu 1994; Shankar and Shetye 1999; Han and Webster 2002) is that river discharge and monsoon rainfall affect sea level in the north Indian Ocean coastal stations. These processes are poorly represented in the simulated sea level here and could explain the underestimated variability in Ko Taphao Noi. The long-term trend is well reproduced (90\% CL) in the Bay of Bengal (see Chennai records; Fig. 9a), the Andaman Sea (Ko Taphao Noi record; Fig. 9), the South China Sea (Cebu record; Fig. 9a), and the East China Sea (see the Kanmen and Busan records; Fig. 9a). The observed sea level trend is underestimated in Mumbai (Fig. 9a) because of an overestimated sea level by climate models at the beginning of the century in this region (see Fig. 6).

Along the Indian coast, the relatively small twentieth-century sea level rise is explained by the local negative contribution from land water storage changes, which compensate for the other positive contributions (Fig. 8). The fall in geoid height and the solid surface response around India associated with the large increase in local groundwater depletion after 1950 explain the reduced sea level rise observed at Mumbai and Chennai during the second half of the twentieth century (Fig. 8). In the Andaman Sea and South and East China Seas, the sea level rise is dominated by the glacier contribution in the first half of the twentieth century and then by both the glacier contribution and the dynamic sea level. 

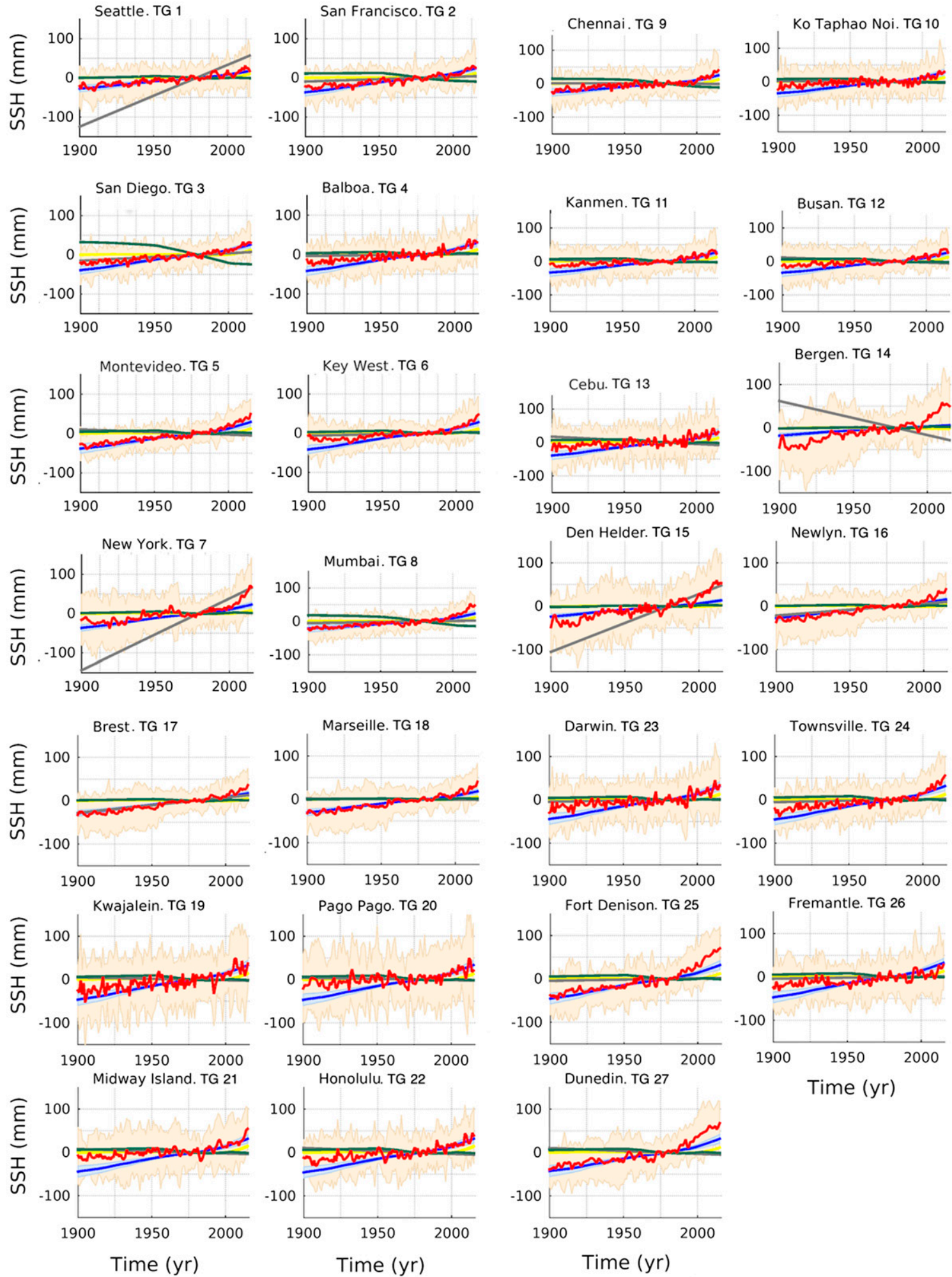

FIG. 8. Contributions to the local annual sea level from observed land water storage changes (green curve), GIA (gray curve), simulated ice sheet mass change (yellow curve), glacier mass change (blue curve), and DSL (including the global thermal expansion; red curve). The shaded areas represent the ensemble spread (1.65 ; i.e., $90 \%$ CL, assuming a Gaussian distribution) of the simulated contributions. 

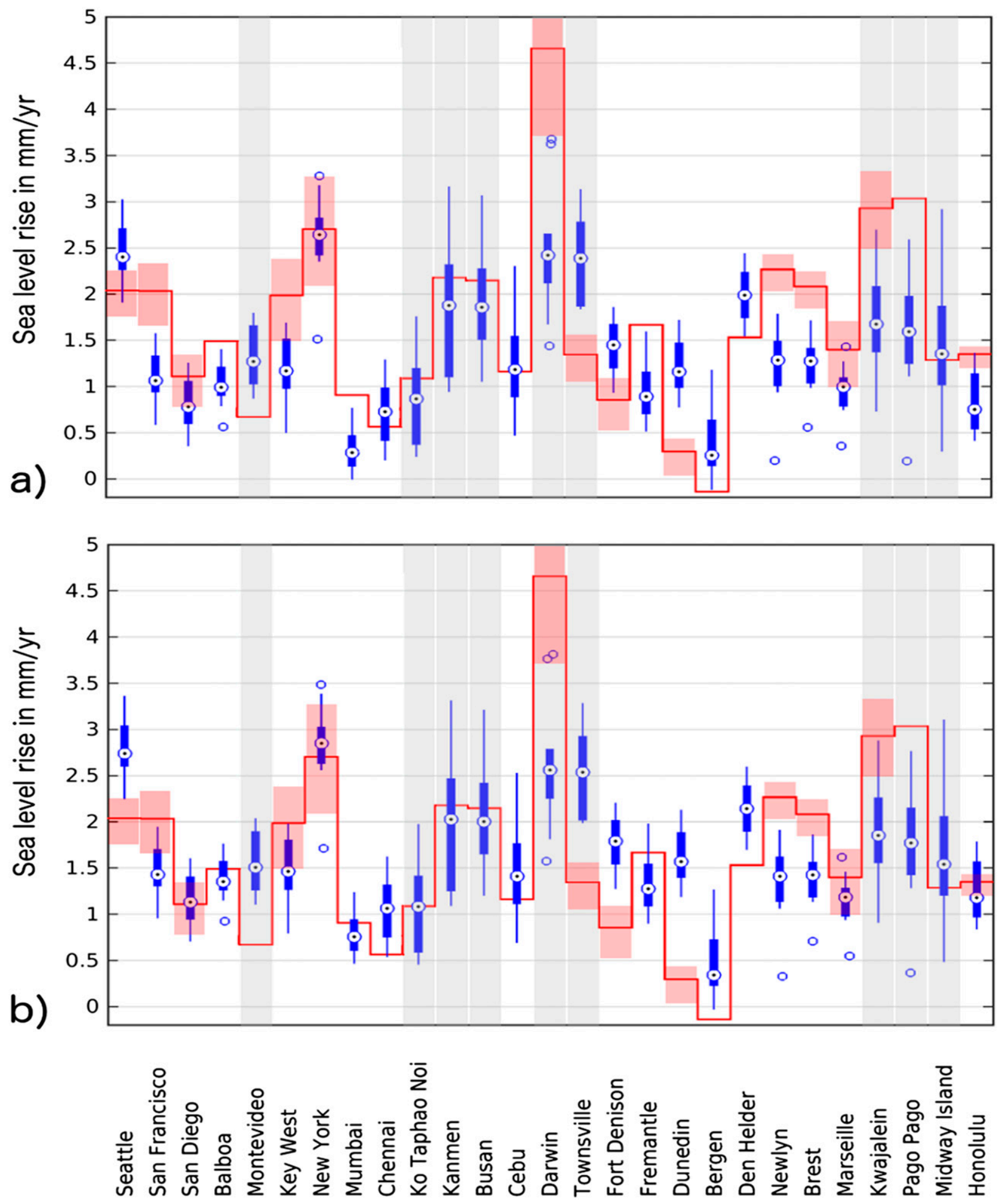

FIG. 9. (a) Box plot of the observed (red) and modeled (blue) sea level trend ( $\mathrm{mm} \mathrm{yr}^{-1}$ ) at each tide gauge station (over the tide gauge record period). On each box, the blue dot inside a white circle indicates the median of the ensemble of modeled sea level trend, and the bottom and top edges of the box indicate the $75 \%$ confidence level. The whiskers extend to cover the $90 \%$ confidence level of the ensemble data (computed as the $1.65 \sigma$ assuming a normal distribution). The outliers are plotted individually using a circle. The red solid line indicates the observed sea level trend by the tide gauge records. The red shaded areas indicate the uncertainty in the observed tide gauge trends deduced from the formal error of the trend calculation and the formal error of the VLM motion estimate (see Table 2) when available. The uncertainty is sizeable only for tide gauge records with VLM estimates. The gray shaded areas indicate the tide gauge records with less than 70 years between the first and the last data. The trends of these tide gauge records are potentially dominated by decadal to multidecadal internal variability. (b) As in (a), but after applying the correction (see text and Fig. 5) to the ensemble of modeled sea level trends. 


\section{3) IN EUROPE}

In Europe, we compare the simulated sea level from climate models with observations from tide gauges located in the North Sea, the Atlantic, and the Mediterranean coast. The case of the Mediterranean Sea needs special attention. At basin scale the interannual to multidecadal Mediterranean sea level is essentially driven by the water exchanges at Gibraltar and closely follows the sea level variability of the Atlantic off the Gibraltar Strait (Bryden et al. 1994; Calafat et al. 2012; Fenoglio-Marc et al. 2013; Adloff et al. 2017). Locally, the Mediterranean sea level shows small departures around the basin average that can occur at interannual to multidecadal time scales under the effect of mesoscale and submesoscale processes (Calafat et al. 2009; Meyssignac et al. 2011). The coarse resolution of global climate models does not enable the simulation of the mesoscale processes and the water exchanges at Gibraltar. It results in a poor representation of the Mediterranean sea level in GCMs (Marcos and Tsimplis 2008; Jordà and Gomis 2013). For this reason the Mediterranean basin is excluded from the sea level simulations based on climate models here. Instead we use the sea level in the Atlantic, off the Gibraltar Strait, as an approximation of the Mediterranean sea level and we compare it with the tide gauge of Marseille.

On European coasts the interannual and multidecadal variability in sea level is well reproduced by climate models except in the North Sea at Bergen and Den Helder (see Table 3 and Figs. 6 and 7). This is potentially due to the deficiency in climate models in reproducing the ocean variability in shallow seas. In contrast, the long-term trends in Europe are not well reproduced by climate models. At Bergen and Den Helder the sea level trend is overestimated whereas it is underestimated at Newlyn and Brest (see Fig. 9a). The fact that the trends are underestimated at both Newlyn and Brest, which are separated by only $\sim 150 \mathrm{~km}$, suggests an issue in the simulated contribution to sea level by climate models or GIA rather than an issue with the VLM correction. In addition, the underestimation is large (see Fig. 9), so it probably does not come from the smallest contributions to the local sea level. The problem is rather linked with the largest contributions to sea level in the region, which are the dynamic sea level contribution, the glacier contribution, and the GIA contribution (in particular, inaccurate GIA could be the reason because there is a significant GIA gradient in this region). A recent estimate of the GIA contribution for the UK sites (Shennan et al. 2012) suggests that our GIA contribution is underestimated by $\sim 0.1 \mathrm{~mm} \mathrm{yr}^{-1}$ in Newlyn, which could explain part of the mismatch in Newlyn and probably in Brest.

As in North America, the twentieth-century sea level trends in Europe are dominated by the GIA contribution in the north close to the former ice sheets (in Fenoscandia and Greenland) such as Bergen and Den Helder. Farther south in Brest and Marseille it is rather dominated by the dynamic sea level contribution and glacier contribution.

\section{4) In THE PACIFIC OCEAN}

In the Pacific, the observed interannual and decadal variability in sea level is well captured by the climate model ensemble (see Table 3) except in Pago Pago where the decadal variability is overestimated by climate models. We also find an underestimation of the sea level variations during extreme events at Pago Pago. Indeed, the observed sea level variations exceed the range of the ensemble spread at Pago Pago during the El Niño extreme events of 1983 and 1998 and the La Niña extreme event of 2011 (Fig. 6). This is in agreement with the observations at the Californian tide gauges (in San Francisco and San Diego; see Fig. 6) and confirms that climate models tend to underestimate the sea level variations associated with extreme ENSO events (part of this discrepancy could be explained by changes in GMSL driven by changes in land water storage associated with ENSO that are inaccurately represented in climate models; Fasullo et al. 2013). In general in the Pacific, the observed long-term trends from tide gauge records are underestimated by climate models (except for Midway Island; see Fig. 9a). This is evident in Honolulu where the tide gauge spans more than 70 years (see Figs. 6 and 9a). Figure 6 shows that the underestimation of the long-term trend of Honolulu is caused by a systematic underestimate of the sea level rate of rise in Honolulu during the first decade of the twentieth century. This is potentially due to an underestimate of the glaciers and ice sheet contributions to sea level rise in the early 1900s (see next section).

The simulated sea level from climate models suggests that, in general in the Pacific, the glacier contribution has dominated the sea level rise during the first half of the twentieth century (Fig. 8). During the second half, the dynamic sea level contribution has increased such that the glacier and dynamic sea level contributions have contributed equally to the observed sea level rise.

\section{5) In Australia And New Zealand}

Around Australia, the observed interannual and decadal variability in sea level is in general fairly well captured by the climate model ensemble (see Table 3) except in Dunedin and Townsville where the 
interannual to multidecadal variability is overestimated by climate models.

For the long-term trends the picture is different. The ensemble mean of climate models significantly overestimates the sea level trends of Dunedin and Townsville and underestimates significantly the trend in Darwin and Fremantle (see Fig. 9a). In the case of Darwin it could be due to an underestimate of the subsidence in the ULR6 GPS solution [estimates by White et al. (2014) indicate a subsidence $0.9 \mathrm{~mm} \mathrm{yr}^{-1}$ larger than ULR6]. Figure 6 shows that the observed variations in Fremantle and Dunedin between 1930 and 1975 are well captured by the climate model ensemble mean. Indeed, the ensemble mean sea level variations depart from the observed sea level variations only in the first and last three decades of the twentieth century (see the Fremantle record in Fig. 6). These departures at decadal time scales are large enough to yield significant differences between the observed and the simulated long-term trends, supporting the hypothesis that the internal variability is the responsible for the longterm trend mismatch. Note that it could also be due to deficiencies of climate models in reproducing the sea level in shallow seas like around Darwin or in the representation of the Indonesian Throughflow and its remote impact along the west coast of Australia like in Fremantle.

\section{d. Impact of the bias correction in the modeled glaciers and ice sheet contribution to twentieth-century sea level}

In a nutshell, climate models reproduce well the multidecadal variability observed by tide gauge records and fairly well the interannual variability (except for tide gauges located in shallow seas and for extreme ENSO events). However, they tend to underestimate systematically the long-term trends. For 5 tide gauges out of 27 (Dunedin, Bergen, Montevideo, Den Helder, and Townsville) the long-term trend is significantly overestimated by climate models (at the $90 \% \mathrm{CL}$ ). For 14 tide gauges out of 27 (Honolulu, Midway Island, Kwajalein, Marseille, Fort Denison, Cebu, Busan, Kanmen, Ko Taphao Noi, Chennai, New York, Key West, San Diego, and Seattle) the observed long-term trend is consistent with the modeled long-term trend (at the $75 \% \mathrm{CL}$ ) and for the remaining 8 tide gauges it is significantly underestimated.

On the basis of differences between models and observations we identified bias corrections for some of the modeled sea level contributions in Part I. For instance, observational evidence points to a larger contribution from the Greenland ice sheet than previously thought (Kjeldsen et al. 2015) in the first half of the twentieth century. This is in line with the finding that the glacier contribution and the Greenland SMB contribution are larger in the early twentieth century when they are computed using temperature reanalyses rather than CMIP5 model estimates (Slangen et al. 2016). We also considered the possibility that ice sheets and the deep ocean are not in equilibrium with twentieth-century climate (Gregory et al. 2013a; Church et al. 2013a) by a nonequilibrium constant contribution to sea level rise, as their response time is likely to be at a century to millennia time scale. Here we adopt the same approach as in Part I. We include these potential contributions and check whether they improve the comparison between climate models and tide gauge records estimates of the long-term trends or not.

For the ice sheets/deep ocean correction we consider the same constant contribution to sea level rise as in Part I and distribute it uniformly over the ocean. For the Greenland and glaciers correction we consider the same global mass correction as in Part I but we distribute it uniformly over the southern part of Greenland (below $70^{\circ} \mathrm{N}$ ) as several studies suggest that this is the main region where climate models differ from observations (Marzeion et al. 2014a; Box et al. 2009; Bjørk et al. 2012) and then determine the regional sea level fingerprint. Note that the exact position of the mass correction does not have to be known as the sea level fingerprints are significantly sensitive to the exact region of mass loss only in the near field. The total sea level correction for the period 1996-2015 with regard to 1901-20 resulting from the sum of the ice sheet/deep ocean correction, the glacier correction, and the Greenland SMB correction is characterized by a sea level rise of about $20 \mathrm{~mm}$ except close to Greenland, where it shows a sea level fall (see Fig. 5d).

Figure $9 \mathrm{~b}$ shows the comparison of modeled sea level trends with observed sea level trends after the bias correction. After correction, the average difference between observed and modeled sea level trends over the range of tide gauges has decreased from 0.37 to $0.12 \mathrm{~mm} \mathrm{yr}^{-1}$ and the standard deviation of the differences has decreased marginally from 0.79 to $0.75 \mathrm{~mm} \mathrm{yr}^{-1}$. With the Darwin record (which is an outlier) excluded, the average difference between observed and modeled sea level trends has decreased from 0.27 to $0.023 \mathrm{~mm} \mathrm{yr}^{-1}$ and the standard deviation of the differences has decreased from 0.77 to $0.73 \mathrm{~mm} \mathrm{yr}^{-1}$. Overall, the bias correction improves climate model estimates of observed sea level trends and also part of the trend spatial variability among climate models (because the standard deviation of the differences between models and tide gauges is improved with the bias correction). But regionally the picture is varied. At low and midlatitudes all tide gauge trends (except Chennai) are better estimated when the correction is applied but at 
high latitudes like at Seattle, New York, or Fort Denison the comparison between observed and modeled sea level is worse with the bias correction. It shows that while the amplitude of the proposed bias correction seems right, its regional pattern needs to be improved. The discrepancy at high latitudes suggests that the ice sheet contribution might be underestimated in the bias correction or that there is some significant error in the GIA correction.

\section{Conclusions}

We have estimated the regional sea level changes between 1900 and 2015 with an ensemble of 12 climate model simulations. The output of the CMIP5 climate model simulations were used to calculate the global and regional sea level changes resulting from dynamic sea level, atmospheric loading, glacier mass changes, and ice sheet SMB contributions. The contributions from groundwater depletion, reservoir storage, and dynamic ice sheet mass changes were estimated from observations as they are not simulated by climate models. All contributions were summed including the GIA contribution to provide an estimate of twentieth-century regional sea level changes and compare it with observations from tide gauge records.

The modeled twentieth-century sea level change shows a GMSL rise of $+12.9 \pm 6 \mathrm{~cm}$ over 1900-2015 (including the ice sheets/deep ocean correction plus glaciers and Greenland SMB correction; see Part I), with substantial regional departures around the GMSL that are within $\pm 100 \%$ of the global signal for more than $90 \%$ of the ocean. The largest departures around the GMSL are localized around the former and present ice sheets (Laurentide, Fenoscandia, Greenland, and Antarctic). They are mostly explained by the GIA contribution. In the rest of the ocean the spatial variations in sea level are dominated by the spatial variations in the dynamic sea level contribution with a dominant contribution from the thermosteric sea level. Locally, around India and the western United States sea level rise has been lower because of groundwater depletion.

The comparison of modeled twentieth-century regional sea level changes with tide gauge records shows that in general the observed multidecadal variability in sea level is well captured by the climate model ensemble (Table 3). This multidecadal variability comes from essentially the dynamic sea level contribution. It is fairly well reproduced here because climate models have been shown to simulate the main features of the principal climate modes of variability such as the interdecadal Pacific oscillation (except in the northwestern tropical Pacific; Power et al. 2006; Meehl et al. 2009; Lyu et al. 2016), the Atlantic multidecadal variability (AMV; e.g., Menary et al. 2012), and the Atlantic meridional overturning circulation (AMOC; e.g., Msadek et al. 2013). The interannual variability observed by tide gauges is only partially captured by climate models (Table 3 ). Indeed, climate models show local deficiencies in simulating sea level changes (e.g., in the Andaman Sea). In the Andaman Sea region the river discharge and monsoon rainfall affect sea level, and the deficiency comes from the fact that these processes are poorly represented in climate models. Tide gauge records also indicate that climate models show deficiencies in simulating the large interannual sea level changes observed during extreme ENSO events (with a tendency to underestimate the sea level changes associated with extreme ENSO events) on the western coast of the United States and in the Pacific islands.

For most of the tide gauge records, climate models tend to underestimate the observed twentieth-century trends. The average difference between observed and modeled sea level trends over the range of tide gauges is $0.27 \pm 0.77 \mathrm{~mm} \mathrm{yr}^{-1}(90 \% \mathrm{CL})$. For the records that span less than 70 years the multidecadal variability in the observed records potentially masks the long-term trend and makes it difficult to assess the modeled sea level. But the other records point to a systematic underestimation of observed sea level trends. The proposed bias corrections for Greenland SMB, glaciers, and the deep ocean/long-term ice sheet all help to reduce the gap between models and observations of sea level, confirming the results of Part I, and result in an average difference between observed and modeled sea level trends of $0.02 \pm 0.74 \mathrm{~mm} \mathrm{yr}^{-1}(90 \% \mathrm{CL})$. The bias correction also improves the spatial variability in modeled sea level trends. But the picture is different in different regions. The bias correction reduces the gap at low and middle latitudes but increases the gap at high latitudes in the northern United States. It suggests that the contribution from ice sheets might be underestimated in climate models or that the GIA correction is not correct since these areas are also areas that are very sensitive to the Earth model and specified ice history.

After the bias correction, some discrepancies between climate models trends and tide gauge records trends persist. These discrepancies are potentially explained by an underestimation of the uncertainty in GIA because the uncertainty due to the ice chronology has not been taken into account in this study. Climate model estimates of regional sea level changes also show that it is important to take into account contributions to sea level changes such as the groundwater depletion contribution 
to account for local deviations of the sea level trends such as the low sea level rise around India.

Although tide gauge records appear as an interesting source of observations to assess sea level changes simulated by climate models, they have some limitations. In addition to the large-scale open ocean climate-related sea level variability that we are assessing here, coastal tide gauge records contain contributions from many coastal and local processes that are absent from or not properly resolved by climate models. These processes include wind-forced coastally trapped waves, local flooding events, hydrological influence from nearby river discharge, and others. They can generate a substantial portion of the signal recorded by the tide gauge records and potentially mask or add to the open ocean variability.

Acknowledgments. The authors acknowledge the World Climate Research Programme's Working Group on Coupled Modelling, which is responsible for CMIP, and thank the climate modeling groups (models listed in Table 3 of this paper) for producing and making available their model output. For CMIP the U.S. Department of Energy's Program for Climate Model Diagnosis and Intercomparison provides coordinating support and led development of software infrastructure in partnership with the Global Organization for Earth System Science Portals. The authors thank the International Space Science Institute (ISSI; Bern, Switzerland) for support of the International Team on contemporary regional and global sea-level rise. Giorgio Spada is funded by a DiSPeA grant of the Urbino University (CUP H32I160000000005).

\section{REFERENCES}

A, G., J. Wahr, and S. Zhong, 2013: Computations of the viscoelastic response of a 3-D compressible Earth to surface loading: An application to glacial isostatic adjustment in Antarctica and Canada. Geophys. J. Int., 192, 557-572, doi:10.1093/gji/ggs030.

Adloff, F., G. Jorda, S. Somot, F. Sevault, T. Arsouze, B. Meyssignac, L. Li, and S. Planton, 2017: Improving sea-level simulation in Mediterranean regional climate models. Climate Dyn., doi:10.1007/s00382-017-3842-3, in press.

Arendt, A., and Coauthors, 2014: Randolph glacier inventoryA dataset of global glacier outlines: Version 4.0. Global Land Ice Measurements from Space (GLIMS) Tech. Rep., 56 pp. [Available online at www.glims.org/RGI/00_rgi40_ TechnicalNote.pdf.]

Argus, D. F., W. R. Peltier, R. Drummond, and A. W. Moore, 2014: The Antarctica component of postglacial rebound model ICE-6G_C (VM5a) based on GPS positioning, exposure age dating of ice thicknesses, and relative sea-level histories. Geophys. J. Int., 198, 537-563, doi:10.1093/gji/ggu140.

Arora, V. K., and Coauthors, 2011: Carbon emission limits required to satisfy future representative concentration pathways of greenhouse gases. Geophys. Res. Lett., 38, L05805, doi:10.1029/ 2010 GL046270.
Balmaseda, M. A., K. Mogensen, and A. T. Weaver, 2013: Evaluation of the ECMWF ocean reanalysis system ORAS4. Quart. J. Roy. Meteor. Soc., 139, 1132-1161, doi:10.1002/qj.2063.

Bilbao, R. A. F., J. M. Gregory, and N. Bouttes, 2015: Analysis of the regional pattern of sea level change due to ocean dynamics and density change for 1993-2099 in observations and CMIP5 AOGCMs. Climate Dyn., 45, 2647-2666, doi:10.1007/ s00382-015-2499-z.

Bjørk, A. A., and Coauthors, 2012: An aerial view of 80 years of climate-related glacier fluctuations in southeast Greenland. Nat. Geosci., 5, 427-432, doi:10.1038/ngeo1481.

Boening, C., J. K. Willis, F. W. Landerer, R. S. Nerem, and J. Fasullo, 2012: The 2011 La Niña: So strong, the oceans fell. Geophys. Res. Lett., 39, L19602, doi:10.1029/2012GL053055.

Bordbar, M. H., T. Martin, M. Latif, and W. Park, 2015: Effects of long-term variability on projections of twenty-first century dynamic sea level. Nat. Climate Change, 5, 343-347, doi:10.1038/nclimate2569.

Bouttes, N., and J. M. Gregory, 2014: Attribution of the spatial pattern of $\mathrm{CO}_{2}$-forced sea-level change to ocean surface flux changes. Environ. Res. Lett., 9, 034004, doi:10.1088/1748-9326/ 9/3/034004.

Box, J. E., L. Yang, D. H. Bromwich, and L.-S. Bai, 2009: Greenland Ice Sheet surface air temperature variability: 1840-2007. J. Climate, 22, 4029-4049, doi:10.1175/ 2009JCLI2816.1.

Bryden, H. L., 1973: New polynomials for thermal expansion, adiabatic temperature gradient and potential temperature of sea water. Deep-Sea Res., 20, 401-408, doi:10.1016/ 0011-7471(73)90063-6.

_ J. Candela, and T. H. Kinder, 1994: Exchange through the Strait of Gibraltar. Prog. Oceanogr., 33, 201-248, doi:10.1016/ 0079-6611(94)90028-0.

Cai, M., 2006: Dynamical greenhouse-plus feedback and polar warming amplification. Part I: A dry radiative-transportive climate model. Climate Dyn., 26, 661-675, doi:10.1007/ s00382-005-0104-6.

Calafat, F. M., D. Gomis, and M. Marcos, 2009: Comparison of Mediterranean sea-level fields for the period 1961-2000 as given by a data reconstruction and a 3D model. Global Planet. Change, 68, 175-184, doi:10.1016/j.gloplacha.2009.04.003.

_ D. P. Chambers, and M. N. Tsimplis, 2012: Mechanisms of decadal sea-level variability in the eastern North Atlantic and the Mediterranean Sea. J. Geophys. Res., 117, C09022, doi:10.1029/2012JC008285.

Carson, M., A. Köhl, and D. Stammer, 2015: The impact of regional multidecadal and century-scale internal climate variability on sea-level trends in CMIP5 models. J. Climate, 28, 853-861, doi:10.1175/JCLI-D-14-00359.1.

,,,--- A. B. A. Slangen, C. A. Katsman, R. S. W. van de Wal, J. Church, and N. White, 2016: Coastal sea-level changes, observed and projected during the 20th and 21st century. Climatic Change, 134, 269-281, doi:10.1007/ s10584-015-1520-1.

Cazenave, A., and Coauthors, 2012: Estimating ENSO influence on the global mean sea level, 1993-2010. Mar. Geod., 35, 82-97, doi:10.1080/01490419.2012.718209.

Chao, B. F., Y. H. Wu, and Y. S. Li, 2008: Impact of artificial reservoir water impoundment on global sea level. Science, 320, 212-214, doi:10.1126/science.1154580.

Chepurin, G. A., J. A. Carton, and E. Leuliette, 2014: Sea level in ocean reanalyses and tide gauges. J. Geophys. Res. Oceans, 119, 147-155, doi:10.1002/2013JC009365. 
Church, J. A., and N. J. White, 2011: Sea-level rise from the late 19 th to the early 21 st century. Surv. Geophys., 32, 585-602, doi:10.1007/s10712-011-9119-1.

- J. M. Gregory, and J. M. Arblaster, 2005: Significant decadal-scale impact of volcanic eruptions on sea level and ocean heat content. Nature, 438, 74-77, doi:10.1038/ nature 04237 .

,-- , N. J. White, S. M. Platten, and J. X. Mitrovica, 2011: Understanding and projecting sea level change. Oceanography, 24, 130-143, doi:10.5670/oceanog.2011.33.

_ D. Monselesan, J. M. Gregory, and B. Marzeion, 2013a: Evaluating the ability of process based models to project sealevel change. Environ. Res. Lett., 8, 014051, doi:10.1088/ 1748-9326/8/1/014051.

_- , and Coauthors, 2013b: Sea-level change. Climate Change 2013: The Physical Science Basis, T. F. Stocker et al., Eds., Cambridge University Press, 1137-1216, doi:10.1017 CBO9781107415324.026.

Clarke, A. J., and X. Liu, 1994: Interannual sea level in the northern and eastern Indian Ocean. J. Phys. Oceanogr., 24, 1224-1235, doi:10.1175/1520-0485(1994)024<1224:ISLITN>2.0.CO;2.

Cogley, J. G., 2009: Geodetic and direct mass-balance measurements: Comparison and joint analysis. Ann. Glaciol., 50, 96100, doi:10.3189/172756409787769744.

Collins, W. J., and Coauthors, 2011: Development and evaluation of an Earth system model-HadGEM2. Geosci. Model Dev., 4, 1051-1075, doi:10.5194/gmd-4-1051-2011.

Cook, A. J., and D. G. Vaughan, 2010: Overview of areal changes of the ice shelves on the Antarctic Peninsula over the past 50 years. Cryosphere, 4, 77-98, doi:10.5194/tc-4-77-2010.

Cornford, S. L., and Coauthors, 2015: Century-scale simulations of the response of the West Antarctic Ice Sheet to a warming climate. Cryosphere, 9, 1579-1600, doi:10.5194/ tc-9-1579-2015.

Dee, D. P., and Coauthors, 2011: The ERA-Interim reanalysis: Configuration and performance of the data assimilation system. Quart. J. Roy. Meteor. Soc., 137, 553-597, doi:10.1002/qj.828.

Delworth, T. L., and Coauthors, 2006: GFDL's CM2 global coupled climate models. Part I: Formulation and simulation characteristics. J. Climate, 19, 643-674, doi:10.1175/JCLI3629.1.

Döll, P., H. Müller Schmied, C. Schuh, F. T. Portmann, and A. Eicker, 2014: Global-scale assessment of groundwater depletion and related groundwater abstractions: Combining hydrological modeling with information from well observations and GRACE satellites. Water Resour. Res., 50, 56985720, doi:10.1002/2014WR015595.

Donner, L. J., and Coauthors, 2011: The dynamical core, physical parameterizations, and basic simulation characteristics of the atmospheric component AM3 of the GFDL global coupled model CM3. J. Climate, 24, 3484-3519, doi:10.1175/2011JCLI3955.1.

Dufresne, J.-L., and Coauthors, 2012: Climate change projections using the IPSL-CM5 Earth System Model: From CMIP3 to CMIP5. Climate Dyn., 40, 2123-2165, doi:10.1007/s00382-012-1636-1.

Dziewonski, A., and D. Anderson, 1981: Preliminary Reference Earth Model. Phys. Earth Planet. Inter., 25, 297-356, doi:10.1016/0031-9201(81)90046-7.

Enderlin, E. M., I. M. Howat, S. Jeong, M.-J. Noh, J. H. van Angelen, and M. R. van den Broeke, 2014: An improved mass budget for the Greenland ice sheet. Geophys. Res. Lett., 41, 866-872, doi:10.1002/2013GL059010.

Farrell, W. E., and J. A. Clark, 1976: On postglacial sea level. Geophys. J. Int., 46, 647-667, doi:10.1111/ j.1365-246X.1976.tb01252.x.
Fasullo, J. T., C. Boening, F. W. Landerer, and R. S. Nerem, 2013: Australia's unique influence on global sea level in 2010-2011. Geophys. Res. Lett., 40, 4368-4373, doi:10.1002/grl.50834.

Fenoglio-Marc, L., A. Mariotti, G. Sannino, B. Meyssignac, A. Carillo, M. V. Struglia, and M. Rixen, 2013: Decadal variability of net water flux at the Mediterranean Sea Gibraltar Strait. Global Planet. Change, 100, 1-10, doi:10.1016/ j.gloplacha.2012.08.007.

Fettweis, X., B. Franco, M. Tedesco, J. H. van Angelen, J. T. M. Lenaerts, M. R. van den Broeke, and H. Gallée, 2013a: Estimating the Greenland ice sheet surface mass balance contribution to future sea level rise using the regional atmospheric climate model MAR. Cryosphere, 7, 469-489, doi:10.5194/ tc-7-469-2013.

E. Hanna, C. Lang, A. Belleflamme, M. Erpicum, and H. Gallée, 2013b: Important role of the mid-tropospheric atmospheric circulation in the recent surface melt increase over the Greenland ice sheet. Cryosphere, 7, 241-248, doi:10.5194/ tc-7-241-2013.

Fiedler, J. W., and C. P. Conrad, 2010: Spatial variability of sealevel rise due to water impoundment behind dams. Geophys. Res. Lett., 37, L12603, doi:10.1029/2010GL043462.

Forget, G., and R. M. Ponte, 2015: The partition of regional sea level variability. Prog. Oceanogr., 137, 173-195, doi:10.1016/ j.pocean.2015.06.002.

Frieler, K., and Coauthors, 2015: Consistent evidence of increasing Antarctic accumulation with warming. Nat. Climate Change, $\mathbf{5}$, 348-352, doi:10.1038/nclimate2574.

Fyfe, J. C., O. A. Saenko, K. Zickfeld, M. Eby, and A. J. Weaver, 2007: The role of poleward-intensifying winds on Southern Ocean warming. J. Climate, 20, 5391-5400, doi:10.1175/ 2007JCLI1764.1.

Gent, P. R., and Coauthors, 2011: The Community Climate System Model version 4. J. Climate, 24, 4973-4991, doi:10.1175/ 2011JCLI4083.1.

Gill, A. E., and P. P. Niller, 1973: The theory of the seasonal variability in the ocean. Deep-Sea Res. Oceanogr. Abstr., 20, 141177, doi:10.1016/0011-7471(73)90049-1.

Gomez, N., J. X. Mitrovica, P. Huybers, and P. U. Clark, 2010: Sea level as a stabilizing factor for marine-ice-sheet grounding lines. Nat. Geosci., 3, 850-853, doi:10.1038/ngeo1012.

Greatbatch, R., 1994: A note on the representation of sea level in models that conserve volume rather than mass. J. Geophys. Res., 99, 12 767-12 771, doi:10.1029/94JC00847.

Gregory, J. M., 2010: Long-term effect of volcanic forcing on ocean heat content. Geophys. Res. Lett., 37, L22701, doi:10.1029/ 2010 GL045507.

, and Coauthors, 2001: Comparison of results from several AOGCMs for global and regional sea-level change 19002100. Climate Dyn., 18, 225-240, doi:10.1007/ s003820100180.

, and Coauthors, 2013a: Twentieth-century global-mean sealevel rise: Is the whole greater than the sum of the parts? J. Climate, 26, 4476-4499, doi:10.1175/JCLI-D-12-00319.1.

, and Coauthors, 2013b: Climate models without preindustrial volcanic forcing underestimate historical ocean thermal expansion. Geophys. Res. Lett., 40, 1600-1604, doi:10.1002/grl.50339.

, and Coauthors, 2016: The Flux-Anomaly-Forced Model Intercomparison Project (FAFMIP) contribution to CMIP6: Investigation of sea-level and ocean climate change in response to $\mathrm{CO}_{2}$ forcing. Geosci. Model Dev., 9, 3993-4017, doi:10.5194/gmd-9-3993-2016. 
Griffies, S. M., and R. J. Greatbatch, 2012: Physical processes that impact the evolution of global mean sea level in ocean climate models. Ocean Modell., 51, 37-72, doi:10.1016/ j.ocemod.2012.04.003.

_- , and Coauthors, 2014: An assessment of global and regional sea level for years 1993-2007 in a suite of interannual CORE-II simulations. Ocean Modell., 78, 35-89, doi:10.1016/j.ocemod.2014.03.004.

Han, W., and P. J. Webster, 2002: Forcing mechanisms of sea-level interannual variability in the Bay of Bengal. J. Phys. Oceanogr., 32, 216-239, doi:10.1175/1520-0485(2002)032<0216: FMOSLI $>2.0 . \mathrm{CO} ; 2$.

Hanna, E., and Coauthors, 2011: Greenland Ice Sheet surface mass balance 1870 to 2010 based on Twentieth Century Reanalysis, and links with global climate forcing. J. Geophys. Res., 116, D24121, doi:10.1029/2011JD016387.

Hay, C. C., E. Morrow, R. E. Kopp, and J. X. Mitrovica, 2015: Probabilistic reanalysis of twentieth-century sea-level rise. Nature, 517, 481-484, doi:10.1038/nature14093.

Hobbs, W., M. D. Palmer, and D. Monselesan, 2016: An energy conservation analysis of ocean drift in the CMIP5 global coupled models. J. Climate, 29, 1639-1653, doi:10.1175/ JCLI-D-15-0477.1.

Holgate, S. J., and Coauthors, 2013: New data systems and products at the permanent service for mean sea level. J. Coast. Res., 29, 493-504, doi:10.2112/JCOASTRES-D-12-00175.1.

Jevrejeva, S., J. C. Moore, A. Grinsted, A. P. Matthews, and G. Spada, 2014: Trends and acceleration in global and regional sea levels since 1807. Global Planet. Change, 113, 11-22, doi:10.1016/j.gloplacha.2013.12.004.

Jordà, G., 2014: Detection time for global and regional sea-level trends and accelerations. J. Geophys. Res. Oceans, 119, 71647174, doi:10.1002/2014JC010005.

— mass components of sea-level variability: The case of the Mediterranean basin. J. Geophys. Res. Oceans, 118, 953-963, doi:10.1002/jgrc. 20060 .

Joughin, I., B. E. Smith, and B. Medley, 2014: Marine ice sheet collapse potentially under way for the Thwaites Glacier Basin, West Antarctica. Science, 344, 735-738, doi:10.1126/science.1249055.

Jungclaus, J. H., and Coauthors, 2013: Characteristics of the ocean simulations in the Max Planck Institute Ocean Model (MPIOM), the ocean component of the MPI Earth system model. J. Adv. Model. Earth Syst., 5, 422-446, doi:10.1002/ jame.20023.

Katsman, C. A., and Coauthors, 2011: Exploring high-end scenarios for local sea-level rise to develop flood protection strategies for a low-lying delta-The Netherlands as an example. Climatic Change, 109, 617-645, doi:10.1007/s10584-011-0037-5.

Kjeldsen, K. K., and Coauthors, 2015: Spatial and temporal distribution of mass loss from the Greenland Ice Sheet since AD 1900. Nature, 528, 396-400, doi:10.1038/nature16183.

Köhl, A., 2015: Evaluation of the GECCO2 ocean synthesis: Transports of volume, heat and freshwater in the Atlantic. Quart. J. Roy. Meteor. Soc., 141, 166-181, doi:10.1002/qj.2347.

Konikow, L. F., 2011: Contribution of global groundwater depletion since 1900 to sea-level rise. Geophys. Res. Lett., 38, L17401, doi:10.1029/2011GL048604.

Kopp, R. E., F. J. Simons, J. X. Mitrovica, A. C. Maloof, and M. Oppenheimer, 2009: Global and local sea level during the last interglacial stage. Nature, 462, 863-867, doi:10.1038/nature08686.

— R. M. Horton, C. M. Little, J. X. Mitrovica, M. Oppenheimer, D. J. Rasmussen, B. H. Strauss, and C. Tebaldi, 2014:
Probabilistic 21st and 22nd century sea-level projections at a global network of tide gauge sites. Earth's Future, 2, 383-406, doi:10.1002/2014EF000239.

Lambeck, K., C. D. Woodroffe, F. Antonioli, M. Anzidei, W. R. Gehrels, J. Laborel, and A. J. Wright, 2010: Paleoenvironmental records, geophysical modeling, and reconstruction of sealevel trends and variability on centennial and longer timescales. Understanding Sea-Level Rise and Variability, J. A. Church et al., Eds., Wiley-Blackwell, 61-121, doi:10.1002/ 9781444323276.ch4.

Landerer, F. W., J. H. Jungclaus, and J. Marotzke, 2007: Regional dynamic and steric sea level change in response to the IPCC-A1B scenario. J. Phys. Oceanogr., 37, 296-312, doi:10.1175/JPO3013.1.

Leclercq, P. W., J. Oerlemans, and J. G. Cogley, 2011: Estimating the glacier contribution to sea-level rise for the period 1800-2005. Surv. Geophys., 32, 519-535, doi:10.1007/s10712-011-9121-7.

Lenaerts, J. T. M., M. R. van den Broeke, W. J. van de Berg, E. van Meijgaard, and P. Kuipers Munneke, 2012: A new, highresolution surface mass balance map of Antarctica (19792010) based on regional atmospheric climate modeling. Geophys. Res. Lett., 39, L04501, doi:10.1029/2011GL050713.

_, D. Le Bars, L. van Kampenhout, M. Vizcaino, E. M. Enderlin, and M. R. van den Broeke, 2015: Representing Greenland ice sheet freshwater fluxes in climate models. Geophys. Res. Lett., 42, 6373-6381, doi:10.1002/2015GL064738.

Lombard, A., G. Garric, and T. Penduff, 2009: Regional patterns of observed sea level change: Insights from a $1 / 4^{\circ}$ global ocean/ sea-ice hindcast. Ocean Dyn., 59, 433-449, doi:10.1007/ s10236-008-0161-6.

Lowe, J. A., and J. M. Gregory, 2006: Understanding projections of sea level rise in a Hadley Centre coupled climate model. J. Geophys. Res., 111, C11014, doi:10.1029/ 2005 JC003421.

Lyu, K., X. Zhang, J. A. Church, A. B. A. Slangen, and J. Hu, 2014: Time of emergence for regional sea-level change. Nat. Climate Change, 4, 1006-1010, doi:10.1038/nclimate2397.

,,,--- and $\mathrm{J} . \mathrm{Hu}, 2016$ : Evaluation of the interdecadal variability of sea surface temperature and sea level in the Pacific in CMIP3 and CMIP5 models. Int. J. Climatol., 36, 3723-3740, doi:10.1002/joc.4587.

Marcos, M., and M. Tsimplis, 2008: Coastal sea-level trends in southern Europe. Geophys. J. Int., 175, 70-82, doi:10.1111/ j.1365-246X.2008.03892.x.

Marzeion, B., M. Hofer, A. H. Jarosch, G. Kaser, and T. Mölg, 2012a: A minimal model for reconstructing interannual mass balance variability of glaciers in the European Alps. Cryosphere, 6, 71-84, doi:10.5194/tc-6-71-2012.

_ A. H. Jarosch, and M. Hofer, 2012b: Past and future sea-level change from the surface mass balance of glaciers. Cryosphere, 6, 1295-1322, doi:10.5194/tc-6-1295-2012.

_ J. G. Cogley, K. Richter, and D. Parkes, 2014a: Attribution of global glacier mass loss to anthropogenic and natural causes. Science, 345, 919-921, doi:10.1126/science.1254702.

— A. H. Jarosch, and J. M. Gregory, 2014b: Feedbacks and mechanisms affecting the global sensitivity of glaciers to climate change. Cryosphere, 8, 59-71, doi:10.5194/tc-8-59-2014.

_ , P. W. Leclercq, J. G. Cogley, and A. H. Jarosch, 2015: Brief communication: Global reconstructions of glacier mass change during the 20th century are consistent. Cryosphere, $\mathbf{9}$, 2399-2404, doi:10.5194/tc-9-2399-2015.

Meehl, G. A., and Coauthors, 2009: Decadal prediction: Can it be skillful? Bull. Amer. Meteor. Soc., 90, 1467-1485, doi:10.1175/ 2009BAMS2778.1. 
Melet, A., and B. Meyssignac, 2015: Explaining the spread in global mean thermosteric sea level rise in CMIP5 climate models. J. Climate, 28, 9918-9940, doi:10.1175/JCLI-D-15-0200.1.

Menary, M. B., W. Park, K. Lohmann, M. Vellinga, M. D. Palmer, M. Latif, and J. H. Jungclaus, 2012: A multimodel comparison of centennial Atlantic meridional overturning circulation variability. Climate Dyn., 38, 2377-2388, doi:10.1007/ s00382-011-1172-4.

Meyssignac, B., and A. Cazenave, 2012: Sea level: A review of present-day and recent-past changes and variability. J. Geodyn., 58, 96-109, doi:10.1016/j.jog.2012.03.005.

_, F. M. Calafat, S. Somot, V. Rupolo, P. Stocchi, W. Llovel, and A. Cazenave, 2011: Two-dimensional reconstruction of the Mediterranean sea level over 1970-2006 from tide gage data and regional ocean circulation model outputs. Global Planet. Change, 77, 49-61, doi:10.1016/j.gloplacha.2011.03.002.

__, M. Becker, W. Llovel, and A. Cazenave, 2012: An assessment of two-dimensional past sea level reconstructions over 1950-2009 based on tide gauge data and different input sea level grids. Surv. Geophys., 33, 945-972, doi:10.1007/ s10712-011-9171-x.

_ X. Xettweis, R. Chevrier, and G. Spada, 2017a: Regional sealevel changes for the twentieth and the twenty-first centuries induced by the regional variability in Greenland ice sheet surface mass loss. J. Climate, 30, 2011-2028, doi:10.1175/ JCLI-D-16-0337.1.

_ C. G. Piecuch, C. J. Merchant, M.-F. Racault, H. Palanisamy, C. MacIntosh, S. Sathyendranath, and R. Brewin, 2017b: Causes of the regional variability in observed sea level, sea surface temperature and ocean colour over the period 1993-2011. Surv. Geophys., 38, 187-215, doi:10.1007/s10712-016-9383-1.

Milne, G. A., and J. X. Mitrovica, 1998: Postglacial sea-level change on a rotating Earth. Geophys. J. Int., 133, 1-19, doi:10.1046/j.1365-246X.1998.1331455.x.

_- W. R. Gehrels, C. W. Hughes, and M. E. Tamisiea, 2009: Identifying the causes of sea-level change. Nat. Geosci., 2, 471478, doi:10.1038/ngeo544.

Mitrovica, J. X., and W. R. Peltier, 1991: On postglacial geoid subsidence over the equatorial oceans. J. Geophys. Res., 96, 20 053-20 071, doi:10.1029/91JB01284.

_- M. E. Tamisiea, J. L. Davis, and G. A. Milne, 2001: Recent mass balance of polar ice sheets inferred from patterns of global sea-level change. Nature, 409, 1026-1029, doi:10.1038/ 35059054

__, N. Gomez, and P. U. Clark, 2009: The sea-level fingerprint of West Antarctic collapse. Science, 323, 753, doi:10.1126/ science. 1166510.

Msadek, R., W. E. Johns, S. G. Yeager, G. Danabasoglu, T. L. Delworth, and A. Rosati, 2013: The Atlantic meridional heat transport at $26.5^{\circ} \mathrm{N}$ and its relationship with the MOC in the RAPID Array and the GFDL and NCAR coupled models. J. Climate, 26, 4335-4356, doi:10.1175/JCLI-D-12-00081.1.

Ngo-Duc, T., K. Laval, J. Polcher, A. Lombard, and A. Cazenave, 2005: Effects of land water storage on global mean sea level over the past half century. Geophys. Res. Lett., 32, L09704, doi:10.1029/2005GL022719.

Pardaens, A. K., J. A. Lowe, S. Brown, R. J. Nicholls, and D. de Gusmão, 2011: Sea-level rise and impacts projections under a future scenario with large greenhouse gas emission reductions. Geophys. Res. Lett., 38, L12604, doi:10.1029/ 2011 GL047678.

Peltier, W. R., 2004: Global glacial isostasy and the surface of the ice-age earth: The ICE-5G (VM2) model and GRACE.
Annu. Rev. Earth Planet. Sci., 32, 111-149, doi:10.1146/ annurev.earth.32.082503.144359.

- D. F. Argus, and R. Drummond, 2015: Space geodesy constrains ice age terminal deglaciation: The global ICE-6G_C (VM5a) model. J. Geophys. Res. Solid Earth, 120, 450-487, doi:10.1002/2014JB011176.

Perrette, M., F. Landerer, R. Riva, K. Frieler, and M. Meinshausen, 2013: A scaling approach to project regional sea level rise and its uncertainties. Earth Syst. Dyn., 4, 11-29, doi:10.5194/ esd-4-11-2013.

Power, S., M. Haylock, R. Colman, and X. Wang, 2006: The predictability of interdecadal changes in ENSO activity and ENSO teleconnections. J. Climate, 19, 4755-4771, doi:10.1175/ JCLI3868.1.

Pritchard, H. D., S. R. M. Ligtenberg, H. A. Fricker, D. G. Vaughan, M. R. van den Broeke, and L. Padman, 2012: Antarctic ice-sheet loss driven by basal melting of ice shelves. Nature, 484, 502-505, doi:10.1038/nature10968.

PSMSL, 2016: Tide gauge data. Permanent Service for Mean Sea Level, accessed 16 April. [Available online at http://www. psmsl.org/data/obtaining/.]

Ray, R. D., and B. C. Douglas, 2011: Experiments in reconstructing twentieth-century sea levels. Prog. Oceanogr., 91, 496-515, doi:10.1016/j.pocean.2011.07.021.

Richter, K., and B. Marzeion, 2014: Earliest local emergence of forced dynamic and steric sea-level trends in climate models. Environ. Res. Lett., 9, 114009, doi:10.1088/1748-9326/9/11/ 114009.

Rignot, E., J. E. Box, E. Burgess, and E. Hanna, 2008: Mass balance of the Greenland ice sheet from 1958 to 2007. Geophys. Res. Lett., 35, L20502, doi:10.1029/2008GL035417.

Roberts, C. D., D. Calvert, N. Dunstone, L. Hermanson, M. D. Palmer, and D. Smith, 2016: On the drivers and predictability of seasonal-to-interannual variations in regional sea level. J. Climate, 29, 7565-7585, doi:10.1175/JCLI-D-15-0886.1.

Ryan, H. F., and M. Noble, 2002: Sea level response to ENSO along the central California coast: How the 1997-98 event compares to the historic record. Prog. Oceanogr., 54, 149-170.

Saba, V. S., and Coauthors, 2016: Enhanced warming of the northwest Atlantic Ocean under climate change. J. Geophys. Res. Oceans, 121, 118-132, doi:10.1002/2015JC011346.

Santamaría-Gómez, A., M. Gravelle, X. Collilieux, M. Guichard, B. M. Míguez, P. Tiphaneau, and G. Wöppelmann, 2012: Mitigating the effects of vertical land motion in tide gauge records using a state-of-the-art GPS velocity field. Global Planet. Change, 98-99, 6-17, doi:10.1016/j.gloplacha.2012.07.007.

Schmidt, G. A., and Coauthors, 2006: Present-day atmospheric simulations using GISS ModelE: Comparison to in-situ, satellite, and reanalysis data. J. Climate, 19, 153-192, doi:10.1175/ JCLI3612.1.

Schoof, C., 2007: Ice sheet grounding line dynamics: Steady states, stability, and hysteresis. J. Geophys. Res., 112, F03S28, doi:10.1029/2006JF000664.

Schotman, H. H. A., 2008: Shallow-earth rheology from glacial isostasy and satellite gravity. Ph.D. thesis, TU Delft, 200 pp.

— , and L. L. A. Vermeersen, 2005: Sensitivity of glacial isostatic adjustment models with shallow low-viscosity earth layers to the ice-load history in relation to the performance of GOCE and GRACE. Earth Planet. Sci. Lett., 236, 828-844, doi:10.1016/j.epsl.2005.04.008.

Sen Gupta, A., N. C. Jourdain, J. N. Brown, and D. Monselesan, 2013: Climate drift in the CMIP5 models. J. Climate, 26, 85978615, doi:10.1175/JCLI-D-12-00521.1. 
Shankar, D., and S. R. Shetye, 1999: Are interdecadal sea level changes along the Indian coast influenced by variability of monsoon rainfall? J. Geophys. Res., 104, 26031-26041, doi:10.1029/1999JC900218.

Shennan, I., G. Milne, and S. Bradley, 2012: Late Holocene vertical land motion and relative sea-level changes: Lessons from the British Isles. J. Quat. Sci., 27, 64-70, doi:10.1002/jqs.1532.

Shepherd, A., and Coauthors, 2012: A reconciled estimate of icesheet mass balance. Science, 338, 1183-1189, doi:10.1126/ science.1228102.

Slangen, A. B. A., M. Carson, C. A. Katsman, R. S. W. van de Wal, A. Köhl, L. L. A. Vermeersen, and D. Stammer, 2014a: Projecting twenty-first century regional sea-level changes. Climatic Change, 124, 317-332, doi:10.1007/ s10584-014-1080-9.

— R. S. W. van de Wal, Y. Wada, and L. L. A. Vermeersen, 2014b: Comparing tide gauge observations to regional patterns of sea-level change (1961-2003). Earth Syst. Dyn., 5, 243 255, doi:10.5194/esd-5-243-2014.

, J. A. Church, X. Zhang, and D. P. Monselesan, 2015: The sealevel response to external forcings in historical simulations of CMIP5 climate models. J. Climate, 28, 8521-8539, doi:10.1175/ JCLI-D-15-0376.1.

,-- C. Agosta, X. Fettweis, B. Marzeion, and K. Richter, 2016: Anthropogenic forcing dominates global mean sea-level rise since 1970. Nat. Climate Change, 6, 701-705, doi:10.1038/ nclimate2991.

_ twentieth-century sea-level rise. Part I: Global mean sea level change. J. Climate, 30, 8539-8563, doi:10.1175/ JCLI-D-17-0110.1.

Spada, G., and P. Stocchi, 2007: SELEN: A Fortran 90 program for solving the "sea-level equation." Comput. Geosci., 33, 538562, doi:10.1016/j.cageo.2006.08.006.

—_, D. Melini, G. Galassi, and F. Colleoni, 2012: Modeling sea-level changes and geodetic variations by glacial isostasy: The improved SELEN code. 37 pp., accessed 15 November 2015. [Available online at http://arxiv.org/abs/ 1212.5061.]

—_, J. L. Bamber, and R. T. W. L. Hurkmans, 2013: The gravitationally consistent sea-level fingerprint of future terrestrial ice loss. Geophys. Res. Lett., 40, 482-486, doi:10.1029/2012GL053000.

Stammer, D., 2008: Response of the global ocean to Greenland and Antarctic ice melting. J. Geophys. Res., 113, C06022, doi:10.1029/2006JC004079.

—_, and S. Hüttemann, 2008: Response of regional sea level to atmospheric pressure loading in a climate change scenario. J. Climate, 21, 2093-2101, doi:10.1175/2007JCLI1803.1.

—, N. Agarwal, P. Herrmann, A. Köhl, and C. R. Mechoso, 2011: Response of a coupled ocean-atmosphere model to Greenland ice melting. Surv. Geophys., 32, 621-642, doi:10.1007/ s10712-011-9142-2.

—-, A. Cazenave, R. M. Ponte, and M. E. Tamisiea, 2013: Causes for contemporary regional sea-level changes. Annu. Rev. Mar. Sci., 5, 21-46, doi:10.1146/annurev-marine-121211-172406.

Stevens, B., and Coauthors, 2013: The atmospheric component of the MPI-M Earth system model: ECHAM6. J. Adv. Model. Earth Syst., 5, 146-172, doi:10.1002/jame.20015.

Sundal, A. V., A. Shepherd, M. van den Broeke, J. Van Angelen, N. Gourmelen, and J. Park, 2013: Controls on short-term variations in Greenland glacier dynamics. J. Glaciol., 59, 883892, doi:10.3189/2013JoG13J019.
Sutterley, T. C., I. Velicogna, E. Rignot, J. Mouginot, T. Flament, M. R. van den Broeke, J. M. van Wessem, and C. H. Reijmer, 2014: Mass loss of the Amundsen Sea Embayment of West Antarctica from four independent techniques. Geophys. Res. Lett., 41, 8421-8428, doi:10.1002/2014GL061940.

Tamisiea, M. E., 2011: Ongoing glacial isostatic contributions to observations of sea-level change. Geophys. J. Int., 186, 10361044, doi:10.1111/j.1365-246X.2011.05116.x.

__ and J. Mitrovica, 2011: The moving boundaries of sea-level change: Understanding the origins of geographic variability. Oceanography, 24, 24-39, doi:10.5670/oceanog.2011.25.

Taylor, K. E., R. J. Stouffer, and G. A. Meehl, 2012: An overview of CMIP5 and the experiment design. Bull. Amer. Meteor. Soc., 93, 485-498, doi:10.1175/BAMS-D-11-00094.1.

Tedesco, M., and X. Fettweis, 2012: 21st century projections of surface mass balance changes for major drainage systems of the Greenland ice sheet. Environ. Res. Lett., 7, 045405, doi:10.1088/1748-9326/7/4/045405.

Tjiputra, J. F., and Coauthors, 2013: Evaluation of the carbon cycle components in the Norwegian Earth System Model (NorESM). Geosci. Model Dev., 6, 301-325, doi:10.5194/ gmd-6-301-2013.

van Vuuren, D. P., and Coauthors, 2011: The representative concentration pathways: An overview. Climatic Change, 109, 5-31, doi:10.1007/s10584-011-0148-z.

van Wessem, J. M., and Coauthors, 2014: Improved representation of East Antarctica surface mass balance in a regional climate model. J. Glaciol., 60, 761-770, doi:10.3189/ 2014JoG14J051.

Veit, E., and C. P. Conrad, 2016: The impact of groundwater depletion on spatial variations in sea-level change during the past century. Geophys. Res. Lett., 43, 3351-3359, doi:10.1002/ 2016 GL068118.

Voldoire, A., and Coauthors, 2013: The CNRM-CM5.1 global climate model: Description and basic evaluation. Climate Dyn., 40, 2091-2121, doi:10.1007/s00382-011-1259-y.

von Salzen, K., and Coauthors, 2013: The Canadian Fourth Generation Atmospheric Global Climate Model (CanAM4). Part I: Representation of physical processes. Atmos.-Ocean, 51, 104-125, doi:10.1080/07055900.2012.755610.

Wada, Y., L. P. H. van Beek, F. C. Sperna Weiland, B. F. Chao, Y.-H. Wu, and M. F. P. Bierkens, 2012: Past and future contribution of global groundwater depletion to sea-level rise. Geophys. Res. Lett., 39, L09402, doi:10.1029/ 2012GL051230.

_ _ M.-H. Lo, P. J.-F. Yeh, J. T. Reager, J. S. Famiglietti, R.-J. Wu, and Y.-H. Tseng, 2016: Fate of water pumped from underground and contributions to sea-level rise. Nat. Climate Change, 6, 777-780, doi:10.1038/nclimate3001.

Watanabe, M., and Coauthors, 2010: Improved climate simulation by MIROC5: Mean states, variability, and climate sensitivity. J. Climate, 23, 6312-6335, doi:10.1175/ 2010JCLI3679.1.

_- M. Chikira, Y. Imada, and M. Kimoto, 2011: Convective control of ENSO simulated in MIROC. J. Climate, 24, 543562, doi:10.1175/2010JCLI3878.1.

Wenzel, M., and J. Schröter, 2010: Reconstruction of regional mean sea-level anomalies from tide gauges using neural networks. J. Geophys. Res., 115, C08013, doi:10.1029/ 2009JC005630.

White, N. J., and Coauthors, 2014: Australian sea levels-trends, regional variability and influencing factors. Earth-Sci. Rev., 136, 155-174, doi:10.1016/j.earscirev.2014.05.011. 
Wöppelmann, G., and M. Marcos, 2012: Coastal sea-level rise in southern Europe and the nonclimate contribution of vertical land motion. J. Geophys. Res., 117, C01007, doi:10.1029/2011JC007469.

C. Letetrel, A. Santamaria, M.-N. Bouin, X. Collilieux, Z. Altamimi, S. D. P. Williams, and B. M. Miguez, 2009: Rates of sea-level change over the past century in a geocentric reference frame. Geophys. Res. Lett., 36, L12607, doi:10.1029/2009GL038720.

Wunsch, C., and D. Stammer, 1997: Atmospheric loading and the oceanic "inverted barometer" effect. Rev. Geophys., 35, 79107, doi:10.1029/96RG03037.
Yin, J., 2012: Century to multi-century sea-level rise projections from CMIP5 models. Geophys. Res. Lett., 39, L17709, doi:10.1029/2012GL052947.

_ S. M. Griffies, and R. J. Stouffer, 2010: Spatial variability of sea-level rise in twenty-first-century projections. J. Climate, 23, 4585-4607, doi:10.1175/2010JCLI3533.1.

Yukimoto, S., and Coauthors, 2012: A new global climate model of the Meteorological Research Institute: MRI-CGCM3Model description and basic performance. J. Meteor. Soc. Japan, 90A, 23-64, doi:10.2151/jmsj.2012-A02. 